\title{
Screening Rules and Portfolio Performance
}

\author{
Angel León \\ aleon@ua.es \\ University of Alicante \\ Address: Ctra. San Vicente SN, E-03080 Alicante, Spain \\ Phone: +34965603400 \\ Lluís Navarro \\ lluis.navarro@,caixabank.com \\ Belén Nieto \\ belen.nieto@ua.es \\ University of Alicante \\ Address: Ctra. San Vicente SN, E-03080 Alicante, Spain \\ Phone and fax: +34965903621
}

\section{This version}

March 5, 2018

\begin{abstract}
We analyze the use of alternative performance measures to rank and select assets. Previous literature centers on the effects of non-normality on rank correlations between orderings. Instead, we select the assets recommended by each performance measure (ordering) and analyze out-ofsample returns of the portfolio that contains them. The overall empirical findings show that performance measures are definitively relevant for subsequent portfolio returns. Assets selected by the Generalized Rachev ratio dominate other selections showing high cumulative returns after the 2008 downturn. The good performance is connected to the fact that these asset returns show high excess kurtosis but positive skewness and are insensitive to the momentum risk factor.
\end{abstract}

Keywords: Performance measure, ranking, stochastic dominance, skewness

JEL: C10, G11, G12 


\section{Introduction}

Securities selection is an important part of the investment process in which so-called screening rules are useful. These rules aim to restrict the investment universe to a reasonably limited set of assets with the best characteristics but without specifying asset allocations. Performance measures (PMs) are examples of screening rules.

Most PMs used for ranking assets are risk-reward ratios, since this is a very important concern for risk managers. The well-known Sharpe (1966) ratio (SR), which relates the mean return to the standard deviation, has been used as a standard for this aim. It is based on the mean-variance paradigm, which requires either elliptical ${ }^{1}$ (e.g., Gaussian distribution) returns or quadratic preferences. However, it is well documented that the deviations from normality of some financial asset return distributions are statistically significant and that, in such cases, the standard deviation underestimates the total risk and generates biased investment rankings. Therefore, ratios that consider a more general framework, such as one-sided reward-risk measures, ${ }^{2}$ or optimal combinations of $\mathrm{PMs}^{3}$ have been proposed. However, the debate on significant differences in the investment applications of these new PMs regarding the SR is still ongoing.

The usual way to compare PM-based candidates in the role of screening rules is based on the Spearman correlations between the rankings. Although the information content provided by each PM may differ, the correlation between two rankings can be strong. If this is the case, one of the two measures could be redundant as a screening rule. Papers that compare PM rank correlations report controversial conclusions. On the one hand, Eling and Schuhmacher (2007) and Eling (2008), among others, conclude that the PM choice becomes irrelevant since they all produce very similar rankings. However, these papers examine only small subsets of PMs and a particular class of assets, such as

\footnotetext{
${ }^{1}$ See Owen and Rabinovitch (1983).

2 See, for instance, Bacon (2008) and Caporin et al. (2014).

${ }^{3}$ See Billio et al. (2015).
} 
mutual funds or hedge funds. Guo and Xiao (2016) reinforce this previous result, showing that if return distributions belong to the location-scale family, then different PMs generate identical rank orderings. On the other hand, other studies show that rankings can be very different, depending on the measure selected. Zakamouline (2011) shows that severe deviations in normality lead to significant shifts in the rankings for hedge funds. León and Moreno (2017), assuming the Gram-Charlier distribution for stock returns, also agree that the PM selection becomes relevant. Caporin and Lisi (2011) find evidence of low rank correlations when using a huge set of different PMs and argue that the results depend on both the type of assets and the sample period. They also show that the rank correlations are time varying and influenced by the sample size. Finally, Magron (2014), using a sample of 24,766 individual investors from a French brokerage, shows that alternative PMs to the SR and specifically the Farinelli-Tibiletti (FT) family result in different rankings.

Our contribution sheds light on the economic fundamentals behind the selection of assets that each PM provides. We do not pay attention to the rankings but we analyze the consequences of different rankings on the investment results by looking at the out-of-sample (OOS) returns of the portfolios that contain the assets recommended by each PM. On the one hand, we analyze whether different portfolios (PMs) generate different subsequent returns. Our study thus complements previous empirical evidence of the relevance of using PMs that are more general than the standard SR. On the other hand, we investigate the possible economic reasons for the different OOS returns. As far as we know, this is the first paper to provide results that link the statistical properties embedded in PMs with the basics of asset pricing.

Specifically, we consider 32 PMs computed daily for all stocks in the Standard and Poor (S\&P) 500 index by using a 264-day rolling window of past returns. The individual stocks are ranked daily on 
the basis of each PM. We select the 5 percent best stocks and create an equally weighted portfolio. ${ }^{4}$ We then compute the next day's return for each portfolio. Caporin and Lisi (2011) point out the need for a dynamic framework because of the instability of PMs over time. Therefore, the rolling window approach is an additional goal of our paper and we employ a sufficiently large window to avoid inconsistencies due to the sample size. Next, we summarize our main results.

First, we compare the portfolios (PMs) by examining the percentages of individual stocks that are simultaneously selected by each pair. We show that portfolio composition is rather similar across portfolios based on measures from the same family. This fact allows us to reduce the number of portfolios (and the dimension of the results) by applying the principal component technique to all portfolios in each family and projecting the OOS returns. In contrast, we find a great difference between the portfolios compositions obtained through the Generalized Rachev (GR) family or valueat-risk ratio (VaRR) and the others.

Second, we compare the characteristics of the OOS return distributions between different portfolios in several ways. We analyze their descriptive statistics including risk-reward ratios and the dynamic conditional correlation (DCC) model of Engle (2002) between pairs of OOS portfolio returns, and we compare the distribution of cumulative returns between pairs of portfolios using stochastic dominance. The results show that the screening rule clearly influences subsequent portfolio returns. In particular, we find that the portfolios containing assets selected by PMs based on quantiles show the largest mean-risk ratios and the lowest correlation with the SR portfolios, and tend to dominate the others.

The last part of the paper investigates the economic reasons behind this good performance. To be more precise, we concentrate on the individual assets selected with the alternative PMs and

\footnotetext{
${ }^{4}$ Note that we do not implement any optimization in the portfolio weight determination to avoid favorable discrimination for a particular measure. Instead, we initially adopt an equal-weighting scheme and, later, in a robustness analysis, valueweight individual stocks.
} 
analyze the distributional properties of their in-sample returns and how they relate to systematic risk factors. Unlike the other PM based returns, we find that GR or VaRR selected stocks returns show positive skewness and are insensitive to the momentum factor. This factor is heavily affected by the negative shock occurred in 2008 . Therefore, this result indicates that stocks selected by measures that look for high probabilistic mass in the right tail of the return distribution suffer a relatively lower negative impact because of the market crisis and can then produce future positive returns quicker.

This paper is outlined as follows. Section 2 briefly presents the PMs used in our analysis. Section 3 describes the data and the portfolio construction. Section 4 presents the empirical results from the comparisons of portfolios composition and returns. Section 5 provides two robustness checks regarding portfolio weights and the rebalancing frequency. Section 6 investigates in detail the statistical and economic characteristics of the stocks selected according to each PM. Finally, Section 7 summarizes the main conclusions.

\section{Performance Measures}

In this study, we consider different PMs allocated into four groups. The first group contains the SR and its extension. The second group refers to PMs based on partial moments with both kappa and FT ratios. The third group includes PMs based on quantiles, such as the value-at-risk (VaR) ratio (VaRR) and the generalized Rachev (GR) ratio. Finally, PMs that do not belong to any particular family are considered the fourth group. Next, we define all the PMs in each group. More details about the specific investment characteristics that these (and other) measures account for can be found in the survey of Caporin et al (2014).

\subsection{The Sharpe ratio and its extension}

A more generalized version of the original SR (Sharpe, 1966, 1994) is defined as

$$
S R(\theta)=\frac{\mu-\theta}{\sigma}
$$


where $\mu$ and $\sigma$ denote the expected return and volatility for the return distribution, respectively. The parameter $\theta$ is the mean return threshold. In the standard case, $\theta$ is the risk-free rate. An extension of the original SR is the adjusted SR (ASR) suggested by Pézier and White (2008), which explicitly adjusts for the skewness, $s k$, and kurtosis, $k u$, of the return distribution:

$$
\operatorname{ASR}(\theta)=S R(\theta)\left[1+\frac{s k}{6} S R(\theta)-\frac{k u-3}{24} S R^{2}(\theta)\right]
$$

\subsection{Performance measures based on partial moments}

In contrast to the standard deviation, lower partial moments (LPMs) define risk as the negative deviations of stock returns, $r$, in relation to the mean return threshold, $\theta$, or the minimal acceptable return, assuming that investors are especially worried about losses. Fishburn (1977), among others, defines an LPM of order $m$ as

$$
\operatorname{LPM}(\theta, m)=\mathbb{E}\left[(\theta-r)_{+}^{m}\right]=\int_{-\infty}^{\theta}(\theta-r)^{m} f(r) d r
$$

where $f(\cdot)$ denotes the probability density function and $(y)_{+}=\max (y, 0)$. The order of the LPM can be interpreted as the investors' risk attitude, with $0<m<1$ for risk-seeking investors, $m>1$ for risk-averse investors, and $m=1$ for risk-neutral investors. Thus, for $m>1$, the higher the $m$, the greater the emphasis on extreme deviations from the threshold $\theta$. Opposite effects arise for $m<1$. The LPM of order 0 is the shortfall probability. The LPM of order 1 is associated with the expected shortfall (see Section 2.3).

Equivalently, the upper partial moment (UPM) of order $q$ is defined as

$$
\operatorname{UPM}(\theta, q)=\mathbb{E}\left[(r-\theta)_{+}^{q}\right]=\int_{\theta}^{\infty}(r-\theta)^{q} f(r) d r .
$$

So, for a given threshold $\theta$, analogous reasoning is applied to select the proper order $q$. We consider two families of PMs within this class: the kappa and FT ratios. 


\subsubsection{Kappa or Sortino-Satchell ratio}

The Sortino and Satchell (SS, 2001) ratio is the mean excess return per unit of risk measured by the LPM

$$
S S(\theta, m)=\frac{\mu-\theta}{\sqrt[m]{\operatorname{LPM(\theta ,m)}}}
$$

Some popular measures, which are nested in equation (5), are the Sharpe-omega ratio (Kaplan and Knowles, 2004) for $m=1$, the Sortino ratio (Sortino and van der Meer, 1991) for $m=2$, and kappa 3 (Kaplan and Knowles, 2004) for $m=3$. It has been verified that $S S(\theta, 1)=\Omega(\theta)-1$, where $\Omega(\theta)$ denotes the omega ratio (Keating and Shadwick, 2002). Note that $\Omega(\theta)=1$ for $\theta=\mu$. Finally, the Bernardo-Ledoit (2000) ratio is the omega ratio for $\theta=0$. Hence, it represents the gainto-loss ratio.

We set the following values for the power of the LPM to consider different investor risk attitudes: $m=10$ (defensive investor), $m=3$ and $m=2$ (conservative investors), $m=1.5$ (moderate investor), and $m=0.8$ and $m=0.5$ (aggressive investors).

\subsubsection{Farinelli-Tibiletti ratio}

Farinelli and Tibiletti (2008) propose a ratio that exclusively looks at the UPMs and LPMs by comparing favorable and unfavorable events:

$$
F T(\theta, q, m)=\frac{\sqrt[q]{U P M(\theta, q)}}{\sqrt[m]{\operatorname{LPM(\theta ,m)}}}
$$

with $q>0$ and $m>0$ for the right and left orders, respectively. The higher the value for $q$, the greater the agent's preference for expected gains. The higher the value for $m$, the greater the investor's dislike of expected losses. Note that equation (6) nests two popular measures: the omega ratio $\Omega(\theta)$ when $q=m=1$ and the upside potential ratio (Sortino et al., 1999) when $q=1$ and $m=2$. Caporin and Lisi (2011) calibrate the parameters to match them with investors' styles. We follow them and keep the same values for $(q, m):(0.5,2)$ for defensive investors, $(1.5,2)$ for conservative investors, 
the omega ratio $(1,1)$ for moderate investors, $(2,1.5)$ for investors seeking potential growth in final wealth; $(3,0.5)$ for aggressive investors, and, finally, the upside potential ratio $(1,2)$.

\subsection{Performance measures based on quantiles}

For this group of measures, we present ratios based on quantiles. First we need to introduce two downside risk measures for the return distribution.

The VaR at the $\alpha$ confidence level is the quantity such that the probability that the return will be lower or equal to this quantity is $\alpha$ :

$$
\operatorname{VaR}(\alpha)=-\inf \{r \mid F(r) \geq \alpha\}
$$

where $F(r)$ represents the cumulative return distribution. And the expected shortfall (conditional $\mathrm{VaR}$, hereafter $\mathrm{CVaR}$ ) measures the expected value of all returns that are lower or equal to the VaR:

$$
\operatorname{CVaR}(\alpha)=-\mathbb{E}[r \mid r \leq-\operatorname{VaR}(\alpha)]
$$

Note that we adopt the common approach of defining VaR $(\mathrm{CVaR})$ as a positive number.

\subsubsection{Generalized Rachev ratio}

The GR ratio (Biglova et al., 2004) relates the CVaR to the power $\delta$ for returns lower than the threshold and to the power $\gamma$ for returns higher than the threshold for the symmetric negative VaR. That is,

$$
G R(\alpha, \theta, \gamma, \delta)=\frac{\mathbb{E}\left[(r-\theta)_{+}^{\gamma} \mid r \geq \operatorname{VaR}(-r ; \alpha)\right]^{\frac{1}{\gamma}}}{\mathbb{E}\left[(\theta-r)_{+}^{\delta} \mid r \leq-\operatorname{VaR}(r ; \alpha)\right]^{\frac{1}{\delta}}},
$$

where $\gamma>0$ and $\delta>0$. We consider 1 percent and 5 percent confidence levels and denote GR1 and GR5, respectively, as the corresponding GR ratios. Again, it is possible to accommodate this ratio for alternative investor profiles using different parameters values. Following Farinelli et al (2009), the values that we employ for $(\gamma, \delta)$ are $(0.8,0.001)$ for defensive investors, $(0.5,0.8)$ for conservative investors, $(0.8,0.8)$ for moderate investors, $(0.5,1)$ for growth investors, $(0.01,0.8)$ for aggressive investors, and $(1,1)$. The last case corresponds to the simple Rachev ratio (Biglova et al., 2004). 


\subsubsection{VaR ratio}

The VaRR was introduced by Caporin and Lisi (2011). With foundations similar to those of the FT ratio, the VaRR relates the positive and the symmetric negative quantiles of the distribution:

$$
\operatorname{VaRR}(\alpha)=\frac{|\operatorname{VaR}(-r ; \alpha)|}{|\operatorname{VaR}(r ; \alpha)|},
$$

where $|\cdot|$ denotes the absolute value function. As before, we set two confidence levels: 1 and 5 percent, and the measures are denoted by VaRR1 and VaRR5, respectively.

\subsection{Other PMs}

The last group includes four ratios representing the mean excess return $(\mu-\theta)$ per unit of risk such that the risk in the denominator is approximated by different dispersion measures. The mean absolute deviation (MAD) ratio proposed by Konno and Yamazaki (1991) uses the mean of $|r-\mu|$ as the risk measure. The minimax ratio (MM) uses the risk measure proposed by Young (1998), $\max \left(r_{(n)},-r_{(1)}\right)$, where $r_{(n)}$ and $r_{(1)}$ denote the ordered statistics corresponding to the maximum and minimum, respectively, of the return sample with size n. Last but not least, the range ratio (Range) uses $\left|r_{(n)}-r_{(1)}\right|$. Finally, we consider Gini's mean difference (Shalit and Yitzhaki, 1984) as the risk measure, defined as

$$
\Gamma=\frac{1}{2} \int_{-\infty}^{\infty} \int_{-\infty}^{\infty}|x-y| f(x) f(y) d x d y,
$$

where $x$ and y denote a pair of realized return values.

We implement the corresponding sample estimations for all the PMs exhibited above.

\section{Data and portfolio construction}

Our sample comprises all individual stocks in the S\&P 500 index from January 2005 to September 2014. It is well known that stock index compositions change over time. These changes can affect the quantity and quality of the information, or the asset's demand because it was either included in or excluded from the index (Jain, 1987; Pruitt and Wei, 1989). To avoid the potential consequences of 
delisting on individual stock returns, we restrict our sample to 424 assets that continuously belonged to the S\&P during our sample period.

We obtain both end-of-day quotes and market capitalization from Bloomberg and compute daily logarithmic returns. As expected, these series are characterized by large deviations from normality; the Jarque-Bera test rejects the assumption of normality for all stocks. Therefore, the dataset seems to be appropriate to compare the role of PMs that account for higher-order moments.

Our sample period contains 2,453 working days. We employ a rolling window of 264 days (approximately one year) to obtain the estimations of the PMs described in Section 2 for each individual stock, setting a zero mean return as the threshold $(\theta=0)$. Specifically, we compute 32 PMs: the SR, the ASR, the SS measures for six different values of order $m$, the FT measures for six alternative combinations of orders $m$ and $q$, the VaRR for both 1 percent and 5 percent, the GR1 and GR5 (also for 1 percent and 5 percent) for six combinations of the power parameters $\gamma$ and $\delta$, respectively, and the MAD, MM, Range, and Gini measures. Then, the last day of each window, the stocks are ranked in decreasing order on the basis of each PM and the first 20 (approximately 5 percent) are chosen to be included in the corresponding PM portfolio. Lastly, we compute the OOS equally weighted stock portfolio return for the next day. We impose this weighting scheme to avoid any arbitrary decisions about optimal allocation. Any other asset allocation criterion could be controversial with the PM on which the asset selection is based. Additionally, De Miguel et al. (2009) find statistical equivalence between the performance of an equally weighted portfolio and that of a Markowitz-optimized portfolio. In any case, Section 5 analyzes the robustness of the results for the value-weighted case. By rolling the window each day, we generate a series of 2,189 OOS returns for each PM-based portfolio. 
In Section 5, we also evaluate the effect of rolling the window and the portfolio construction each month.

\section{Results}

We analyze whether the use of different criteria for ranking and selecting assets leads relevant differences. To do so, we compare 32 portfolios containing assets selected by each of the 32 PMs in several ways. First, we analyze the portfolio compositions. Second, we look at descriptive statistics of the OOS portfolio returns in both static and dynamic frameworks. Third, we compare the different portfolios by testing for both first-order stochastic dominance (FSD) and second-order stochastic dominance (SSD) in the return distribution.

\subsection{Portfolio composition}

For each of the 2,189 days in which the 32 portfolios are constructed with the best 20 individual assets, we count how many assets are selected simultaneously using two different measures. Table 1 displays the median value during the 2,189 days of the percentage of coincident assets when comparing two alternative measures.

Regarding coincident assets for the SR and other measures, we find that the median is 100 percent for the ASR; relatively high (above 60 percent) for the SS, MAD, MM, Range, Gini and some FT ratios. In contrast, the selected assets are generally different when other measures are used. The percentage of coincidences varies between 15 percent and 25 percent on median when comparing the SR with all the GR ratios and the two VaRRs. ${ }^{5}$ Comparing PMs each other we find that the lower number of coincident assets is again for GR and VaRR ratios. Of course, the percentage of coincidences increases when comparing pairs of measures within the same family, as expected.

\footnotetext{
${ }^{5}$ In fact, the maximum percentage of coincident assets in the complete OOS period between GR or VaRR and any of the other measures is about 60 percent.
} 
However, this is not the case for the FT family. The percentage of coincidences can be as small as 20 percent for different parameter values, suggesting the importance of investment style.

The evidence in Table 1 allows us to conclude that assets selected by alternative measures are different.

\subsection{Portfolio returns: Static analysis}

According to Table 1, the PM selection can produce portfolios with very different compositions. In this section, we study whether different compositions imply significant differences in OOS portfolio returns. Since portfolios from the same PM family have similar compositions, to reduce the amount of information, we apply principal component analysis to summarize in a single portfolio the information content of all the portfolios in each family, particularly for the SS, FT, and GR portfolio groups. Therefore, from now on, we analyze the returns for 12 portfolios instead of 32 portfolios.

Table 2 displays standard descriptive statistics on the portfolio returns computed using the entire OOS period (January 2006 to September 2014). Panel A presents the mean, maximum, minimum, standard deviation, beta, skewness, and excess kurtosis. ${ }^{6}$ Complementary information about risk is provided by the $\mathrm{VaR}$ and $\mathrm{CVaR}$ at 1 percent and 5 percent.

With the exceptions of GR5, VaRR1 and Range portfolios, all portfolios show a higher mean return than the SR portfolio. VaRR5 portfolio exhibits the largest mean return, followed by GR1, with mean returns 4.4 and 2.9 times the SR portfolio, respectively. VaRR5 portfolio return also shows the largest range (distance between the maximum and the minimum), standard deviation, and beta. All portfolio returns show negative skewness and excess kurtosis, being GR5, MM and Range the portfolios with the largest negative skewness and FT, the two GR and VaRR those with the largest kurtosis. Significant differences among portfolios in terms of $\mathrm{VaR}$ (5 percent), CVaR (5 percent), or

\footnotetext{
${ }^{6}$ The mean, maximum, minimum, and standard deviation are expressed as percentages. The market betas are computed by employing the S\&P 500 index as a proxy for the market portfolio and using a monthly frequency.
} 
MDD are not observed. Only for the case of VaRR5 these risk values are larger than the rest. Note that this portfolio contains the assets with the lowest VaRR (5 percent) and produces the maximum value for $\mathrm{VaR}$ (1 and 5 percent). This fact illustrates how different can be the distributional properties of in-sample and out-of-sample returns.

To visualize whether the greatest risk for the VaRR5 portfolio is compensated for by its largest mean return, Figure 1 presents the mean-risk ratios based on the risk measures provided in Table 2. As shown, the VaRR5 portfolio exhibits the largest mean-risk compensation. The difference between this portfolio and the others is remarkably large. All ratios for the VaRR5 are more than 1.3 times the respective ratios for the GR1 portfolio, which is the second best portfolio in terms of risk compensation. Additionally, we find that all mean-risk ratios are larger for eight out of 11 alternative PMs than for the SR.

Panel B of Table 2 displays the correlation between the different portfolio returns. Comparing to the SR, the lowest correlations correspond to the four portfolios based on either GR or VaRR measures (around 80 percent), consistently with the results about the portfolio composition. Note also that these four portfolios show the lowest levels of return correlation with the other portfolios. On the contrary, the ASR, SS, MAD, Range, and Gini portfolios are highly correlated with the SR (more than 97 percent).

For the rest of the paper, to facilitate visual comparisons between portfolios, all the figures contain two graphs: one for the five portfolios with the lowest correlations with the SR (GR1, GR5, VaRR1, VaRR5, and MM) and the other for the remaining six portfolios.

\subsection{Portfolio returns: Dynamic analysis}

In this section, we study the behavior of the PM portfolios in a dynamic framework. First, we start estimating the DCC of Engle (2002) between the SR and any other portfolio returns. These series are displayed in Figure 2. The daily conditional correlations between the SR and the ASR, SS, FT, MAD 
and Gini returns are very high and quite stable in time. Correlation between SR and Range is relatively high on average but shows larger variability. For the remaining PMs, the conditional correlations are lower and highly time varying. Generally, the correlations are positive but decrease considerably during the crisis period for some pairs, particularly in the GR1, GR5, VaRR1, and VaRR5 cases.

Second, Figure 3 represents the spreads between the cumulative returns on each portfolio and the SR during the OOS period. As seen in the bottom graph, the spreads are much lower for the portfolios most correlated with the SR (compare the scale in the vertical axis). In this case, the spreads show both positive and negative values depending on the time period. The best performance is shown by Gini, MAD and ASR with spreads around zero up to the end of 2009 and positive from this point to the rest of the OOS period. Visual analysis of the top graph indicates in contrast that the VaRR5, GR1 and MM cumulative returns are generally higher than the SR cumulative returns during the whole period. GR5 and VaRR1 produce returns higher than for the SR in the pre-crisis period but their spreads are around zero or negative after the crisis.

Therefore, summing the results up to this point, we conclude that very different patterns in the portfolio OOS return distribution are observed for stocks selected by different PMs and the VaRR5 and GR1 measures seem to be the most appropriate screening rules.

\subsection{Stochastic dominance analysis}

To compare more rigorously the complete distribution of returns for different PM-based portfolios, we employ the stochastic dominance tool. Taking into account the weak assumptions of non-satiation and risk aversion for investor preferences, we can compare the empirical cumulative distribution functions (CDFs) for each pair of cumulative returns in terms of FSD and SSD. We use the DavidsonDuclos (2000, hereafter DD) test. Given a random sample of $N$ independent drawings of observations $\left(y_{i, A}, y_{i, B}\right), i=1, \ldots, N$, from two populations $\mathrm{A}$ and $\mathrm{B}$, the statistic for testing the null that neither $\mathrm{A}$ nor B dominates the other for order $s$ has the following form: 


$$
T^{S}(x)=\frac{\widehat{D}_{A}^{S}(x)-\widehat{D}_{B}^{S}(x)}{\sqrt{\widehat{V}^{S}(x)}}
$$

such that

$$
\widehat{D}_{j}^{s}(x)=\frac{1}{N(s-1) !} \sum_{i=1}^{N}\left(x-y_{i, j}\right)^{s-1} I\left(y_{i, j} \leq x\right)=\frac{1}{N(s-1) !} \sum_{i=1}^{N}\left(x-y_{i, j}\right)_{+}^{s-1}, j=A, B
$$

where $I($.$) is an indicator function equal to one when the argument is true and zero otherwise. Note$ that, for $s=1, \widehat{D}$ is the empirical distribution function that estimates the population CDF; for $s>1, \widehat{D}$ is simply the sum of independent and identically distributed variables. Finally, $\widehat{V}$ is an estimate for the variance of the numerator of the statistic (11):

$$
\widehat{V}^{s}=\widehat{V}_{A}^{S}+\widehat{V}_{B}^{S}-2 \widehat{V}_{A B}^{S}
$$

with

$$
\begin{gathered}
\widehat{V}_{j}^{S}(x)=\frac{1}{N}\left[\left(\frac{1}{N((s-1) !)^{2}} \sum_{i=1}^{N}\left(x-y_{i, j}\right)_{+}^{2(s-1)}\right)-\widehat{D}_{j}^{S}(x)^{2}\right], j=A, B \\
\widehat{V}_{A B}^{S}(x)=\frac{1}{N}\left[\left(\frac{1}{N((s-1) !)^{2}} \sum_{i=1}^{N}\left(x-y_{i, A}\right)_{+}^{2(s-1)}\left(x-y_{i, B}\right)_{+}^{2(s-1)}\right)-\widehat{D}_{A}^{S}(x) \widehat{D}_{B}^{S}(x)\right] .
\end{gathered}
$$

Under the null, $T$ is asymptotically distributed as a standard normal variable. We implement the DD test for first- and second-order dominance. We set 100 different values for $x$, which are obtained by dividing the entire possible range $\left(\max \left(y_{i, j}\right)-\min \left(y_{i, j}\right)\right.$, for $\left.j=\mathrm{A}, \mathrm{B}\right)$ into 100 grids. To control for the joint test size, the inference is based on the studentized maximum modulus distribution with a 5 percent critical value of $3.254 .^{7}$ Therefore, we compute the number of significant positive statistics $(T>3.254)$ and the number of significant negative statistics $(T<-3.254)$. We denote the total numbers of significant positive and negative statistics DD+ and DD-, respectively. When the number of

\footnotetext{
${ }^{7}$ The studentized maximum modulus is the maximum absolute value of a set of independent unit normal variables that are studentized by the standard deviation. Critical values for infinite degrees of freedom are tabulated by Stoline and Ury (1979).
} 
significant positive (negative) statistics DD+ is equal or higher than 50 , the null is rejected and we conclude that B (A) dominates A (B).

Panels A and B of Table 3 report the FSD and SSD results, respectively. Since we carry out the comparisons in pairs, DD+ (DD-) higher than 50 implies that the portfolio indicated in the first row (column) dominates the portfolio indicated in the first column (row). ${ }^{8}$ Confirming the visual conclusion from Figure 3, we find that the VaRR5, GR1, and MM are better than the SR in terms of both marginal utility (FSD) and risk (SSD) in more than 90 percent of the values at which the distributions are compared. Additionally, GR5, Gini and ASR dominate SR in both first and second orders. In contrast, SS and Range portfolio returns are dominated by SR.

Other comparisons show that definitively GR1 is the best portfolio; VaRR5 dominates the rest excluding GR1, MM is the third dominating portfolio and Gini is better than most portfolios (SR, ASR, SS, FT, VaRR1, MAD and Range). On the other side, SS and Range are the worst PM based portfolios since their returns are systematically dominated by the other portfolio returns.

\section{Robustness checks}

The previous empirical analysis implies some arbitrary decisions. This section checks whether the results in Section 4 may be invariant to some changes in the computation of the OOS portfolio returns. Specifically, we analyze the effects of the frequency of portfolio rebalancing and the weighting scheme for individual stocks in the portfolio.

\subsection{Montbly portfolio rebalancing}

Daily portfolio rebalancing can produce important transaction costs. These costs depend on the level of replacement of individual stocks that each new PM-based ranking produces. As a proxy for transaction costs, for each PM (the original 32 PM-based portfolios) and each day we compute the

\footnotetext{
${ }^{8}$ In the SSD case, we change the order in the numerator of the T-statistic so that DD+ and DD- can be interpreted in the same sense as in panel A of Table 3.
} 
percentage of stocks that are replaced. The results indicate that the highest transaction cost would be supported when stocks are selected by SR: on average, 8.3 percent of the individual stocks are replaced daily. Similar numbers are obtained for the ASR, the six SS ratios, and the MAD, MM, Range, and Gini measures. When the FT ratios are used, the level of replacement depends on the parameters going from 8.0 percent for $\mathrm{FT}(1,1)$ to 4.3 percent for $\mathrm{FT}(3,0.5)$. Finally, for the GR orderings, the transaction costs are similar within each family but much lower than for the other PMs with a replacement rate around 4.6 or 2.5 percent when $\alpha$ equals 5 or 1 percent, respectively. Finally, the average levels of replacement are $6.8 \%$ and $3.7 \%$ for VaRR5 and VaRR1, respectively. Therefore, we can conclude that the benefits of using PMs alternative to the SR would persist if we look at returns net of transaction costs.

Despite the previous results, we repeat the analysis in Section 4 but now carry out the asset ranking and selection only once a month, thus maintaining a buy-and-hold portfolio strategy every day within the month where stocks are equally weighted. The top graph in Figure 4 shows, as before, that GR1 spread is positive most of the time, except during the financial crisis period when most spreads drop sharply and reach large negative values. In fact, the GR1 spread is higher on average than in the case of daily rebalancing. On the other hand, the bottom graph in Figure 4 shows that this lowfrequency rebalancing scheme produces more portfolios with positive spreads during almost the whole period and higher on average than in Figure 3. Note that Range (one of the two worst portfolios with daily rebalancing) displays now the second largest spread.

Results in Table 4 indicate that, with the exception of the MAD and MM portfolios, all the other portfolios dominate the SR portfolio. In the whole comparison, generally, the GR1, Range, FT and VaRR5 are the best, in this order, while the MAD portfolio is clearly the worst. 


\subsection{V alue-weighted portfolios}

In this case, the composition of the 32 initial portfolios is the same as in Section 5.1 with monthly rebalancing, but the weight on each individual asset is given by its market capitalization. In this case, the maintenance costs are thus much lower than in the equally weighted scheme. After that, and again, we obtain the representative portfolio for each family, applying principal component analysis.

Figure 5 displays the cumulative return spreads regarding the SR. Comparing Figures 5 and 4, we observe that GR1 and Range show again positive spreads and even higher than in the equallyweighted case. In contrast, the value-weighted strategy improves considerably the returns on the MM portfolio and, moreover, reduces the GR5 spread which is continuously negative from February 2008 to the end.

Panels $\mathrm{A}$ and $\mathrm{B}$ of Table 5 compare the cumulative returns in terms of FSD and SSD, respectively. With the exception of GR5 and ASR, all portfolio returns perform better than the SR portfolio. Consistent with the visual representation, GR1 and MM are the best portfolios. Additionally, Range dominates eight other portfolios and VaRR5 dominates 7 other portfolios. The portfolios containing stocks selected by GR5 and ASR show the worst returns.

\section{What is behind stock selection?}

Previous results indicate that the use of different PMs in selecting a subset of assets not only produces different selections but also different asset returns in the next period. Of the 12 ranking strategies analyzed, the GR1 ratio is the best option in our sample period. After the strong generalized decrease in returns in 2008, stocks selected by this PM are the ones that show high reversion in a relatively short term. They produce OOS cumulative returns between 12 percent and 45 percent higher than the stocks selected by SR. In addition, the OOS returns that produce stocks selected by VaRR5 are higher than most other selections and the VaRR5 portfolio dominates at least seven out of 11 portfolios in the three stochastic dominance analysis presented in previous sections. The question now is why? This 
section explains the source of the benefits of picking assets using GR or VaRR ratios. In this case, we want to analyze the characteristics of the stocks selected by different PMs and thus we work with the in sample returns on the 20 stocks selected by each of the 32 PM (with different parameter values).

First, we look at the distributional properties. Using the same window that has been used to compute the PMs (the previous 264 days), we compute the rolling moments for each individual stock return. Then, we calculate the average across each set of 20 stocks selected by each PM. Figure 6 display these rolling moments for the six GR measures and the SR case. The first graph shows that that stocks selected by GR ratios have lower means than stocks selected by SR. However, the difference between means is reduced from December, 2009. Standard deviations are similar, but slightly lower for stocks selected by SR. The two effects together illustrate the fact that stocks selected by the GR ratio are different from those selected by SR in a very high proportion since their Sharpe ratios are relatively low. The most important differences are found in the third and fourth moments of the returns distribution. GR ratios select stocks with much higher levels of kurtosis and positive skewness. Therefore, this measure recommends stocks with relatively more probabilistic mass in the right tail of the return distribution and thus with lower exposition to negative shocks. In addition, we observe that both kurtosis and specially skewness are highly time-varying for GR selected stocks. It is true that the level of positive skewness decreases sharply during the 2008-09 recession but it is still twice the level shown by SR selected stocks.

The second analysis consists on investigating which types of systematic risk the stocks selected by different PM are exposed to. Then, we regress the in sample returns on each equally weighted portfolio containing the 20 stocks selected by each PM on seven well-known aggregate risk factors: the five factors suggested by the Fama-French (2015) model, the momentum factor and the quality factor. The regression is the following: 


$$
\begin{gathered}
R_{i t}-R_{F t}=a_{i}+b_{i}\left(R_{M t}-R_{F t}\right)+s_{i} S M B_{t}+h_{i} H M L_{t}+r_{i} R M W_{t}+c_{i} C M A_{t}+w_{i} W M L_{t}+ \\
q_{i} Q M J_{t}+u_{i t}
\end{gathered}
$$

where $R_{i t}$ is the return on month $t$ of the portfolio that contains the 20 stocks selected by the PM $i$, where $i=1,2, \ldots, 32$, at the end of the corresponding month; $R_{F t}$ is the proxy for the risk-free rate; $R_{M t}$ is the return on the market portfolio; $S M B_{t}$ is the size factor, computed as the difference between the returns on small and big firms; $H M L_{t}$ represents the value factor and is the difference between the returns on firms with high and low book-to-market ratios; $R M W_{t}$ represents the profitability factor, computed as the difference between the returns on stocks of firms that have robust and weak profitability; $C M A_{t}$ is the difference between the returns on stocks of low- and high-investment firms; $W M L_{t}$ is the momentum factor consisting on the difference in returns on stocks with the largest prior return and stocks with the lowest prior return, and $Q M J_{t}$ is the quality factor proposed by Asness, Frazzini and Pedersen (2017) which is the difference between the returns on stocks from high and low quality firms. ${ }^{9}$

We obtain the monthly series for the six first factors and the risk-free rate from Kenneth French's data library ${ }^{10}$ while data for the quality factor comes from Applied Quantitative Research website. ${ }^{11}$ The estimated sensitivities, $t$-values, and $R^{2}$ coefficients for each portfolio are provided in Table 6.

As expected, all the portfolios respond positively and significantly to changes in the market factor. SR, ASR, MAD, MM, Range, Gini, and the six SS portfolios show similar betas regarding other risk factors. They are positively exposed to the size and momentum factors and negatively exposed to

\footnotetext{
${ }^{9}$ Quality is defined as a combination of four firm characteristics: profitability, payout, safety and growth. See Asness, Frazzini and Pedersen (2017) for details.

${ }^{10} \mathrm{http}: / /$ mba.tuck.dartmouth.edu/pages/faculty/ken.french/data library.html.

11 https://www.aqr.com/library/data-sets/
} 
the investment factor. This means that stocks on these portfolios are closer to be small firms and aggressive in investment. Additionally, their returns suffer from the high excess kurtosis and negative skewness that characterize the momentum factor in a sample period that includes a recession. Similar results are found for the FT portfolios although the intensity of these risks depends on the parameters values. The risk exposition of $\mathrm{FT}(1,1)$ and $\mathrm{FT}(1,2)$ is practically the same as the previous portfolios. Remember that these are two special cases: the omega and the upside potential ratios, respectively. For other parameters values, the resulting portfolio has no size risk. When the power of the numerator is higher than the power of the denominator in the FT ratio, the portfolio is not affected by the momentum risk. And the maximum exposition to the investment risk is for the portfolio based on the FT ratio with a power lower than 1 in the denominator. The two portfolios based on VaRR ratios show insignificant size and momentum betas, while they are the unique portfolios with value risk.

The main difference between the stocks selected by GR measures and the others is that they are not exposed to any other type of risk different form the market one. These results indicate how the distributional properties of returns (which are used to select stocks under different PM) are connected with the economic fundamentals of asset pricing. Specifically we obtain that to put attention on the probabilistic mass on the tails of the distribution by looking for a higher mass in the right tail allows finding stocks uncorrelated with a multitude of risks. It is interesting to point out the positive exposure of all but GR portfolios to the momentum factor. This factor is characterized by high levels of kurtosis and negative skewness and then it is largely affected by the negative shock occurred in 2008. The positive slope of the other portfolio returns on this factor revels the fact that most stocks suffer from the dramatic crash. However, the use of the GR ratio avoids selecting stocks with returns negatively skewed and then its selection is uncorrelated with the momentum factor. This conclusion was already suggested by the pattern of dynamic correlations in Figure 2 where we see the opposite direction between returns on GR or VaRR portfolios and the other portfolios during 2008 and 2009. 
Therefore, the lower impact that the crisis has on returns of GR or VaRR selected stocks helps in their post-crisis relatively quick recovery. This is confirmed by their superior performance in cumulative OOS returns.

Empirical results from previous literature on the connection between skewness for equity returns and the cross-section of expected returns are mixed. Papers that employ implied skewness estimated from option prices tend to find a positive relation (Xing, Zhang and Zhao, 2010; Rehman and Vilkov, 2012). While Amaya et al (2015), among others, show that the strategy of buying stocks with negative skewness and selling stocks with positive skewness produces not only positive future returns but also positive and significant risk-adjusted future returns. Therefore, the authors conclude that there is a negative relation between current skewness and future returns. Estimated alphas in the Table 6 cannot be interpreted in the same sense as in previous analysis. Our aim is to understand the risk characteristics of stocks selected by different PMs and we then use in-sample returns (and not future returns) in the regression model. ${ }^{12}$ In any case, we argue in favor of a positive relation since we find that the selection of stocks with positive skewness through the use of GR ratios generates positive and large subsequent (OOS) returns. Curiously, Amaya et al (2015) compute realized skewness daily from intraday returns to sort and group stocks into skewness based portfolios. However, they also evaluate portfolios based on skewness that is measured using historical daily returns. Specifically, they find that, when skewness is computed over 6-month, 12-month (as in our case), or 24-month window of past daily returns, both future return and the four-factor alpha are significantly higher for the portfolio with the stocks showing the most positive skewness than the portfolio containing the most negative skewed stocks.

\footnotetext{
12 We repeat the estimations of equation (12) using the next month average return on the 20 stocks selected by each PM instead of the return in the month of the selection. Results regarding the slopes are similar to those in Table 6 . The important difference is found for alphas. Although they are now not significantly different from zero for any PMs, they are positive only for GR1 cases and negative for the rest. This illustrates again the higher OOS returns that the GR1 selection produces.
} 
Lastly, to confirm that the positive skewness of stocks selected by GR or VaRR measures is responsible for the negative or zero slope of these stock returns to the momentum factor, we take now daily data on the factor from the beginning of the sample period, January 2005. We compute rolling moments with 264-day window of past returns on the factor. Specifically, we are interested on the time varying pattern of skewness since this moment is specially negative and large in bad times. We then compare the rolling skewness for the factor and for the stocks selected by the PMs. The positive sensitivity of any portfolio different from GR or VaRR to the momentum factor suggests that their skewness decrease during the crisis period. Therefore, the correlation between rolling skewness of the factor and these portfolios should be positive. Equivalently, the correlation should be zero or negative in the case GR or VaRR. We find that this correlation is around 11\% in the case of SR or ASR selected stocks, $10 \%$ on average for the stocks selected by the six SS measures, $15 \%$ on average for the stocks selected by the six FT ratios, and around 18\% for Gini, Range, MAD or MM ratios. In contrast, the stocks selected by GR5 or GR1 ratios show a much smaller correlation of 2\% and 5.8\%, respectively, on average. And the correlation is even negative in the case of VaRR selected stocks, with values of $5.4 \%$ and $-3.3 \%$ for VaRR5 and VaRR1, respectively. Figure 7 displays the series of rolling skewness for one selected GR5 portfolio, the VaRR5 portfolio, and the momentum factor. As known, this risk factor has negative skewness on average which is strongly accentuated in periods of negative returns. The skewness is small but positive on average for the stocks selected by VaRR5 and clearly positive, and very large in some moments, for stocks selected by GR5. The time varying behavior of the three series illustrates the low or negative correlation between them.

\section{Conclusions}

This paper examines the use of PMs for ordering and selecting assets. The comparison between different PMs as screening rules was previously addressed by rank correlations between pairs of orderings associated with two PMs. Instead, our contribution sheds light on the economics behind the 
selection of assets due to each PM. We analyze the consequences of different rankings on the investment results by looking at the OOS returns of the portfolios that contain the assets recommended by each PM. On the one hand, our study thus complements previous empirical evidence on the relevance of using PMs more general than the standard SR. On the other hand, this study provides results that link the statistical properties embedded in the PMs with the basics of asset pricing.

We work with different PMs, including the Sharpe and the Adjusted Sharpe ratios, four ratios with the mean in the numerator and different measures of dispersion in the denominator, six Kappa ratios, six Farinelly-Tibiletti ratios, twelve Generalized Rachev ratios and two VaR ratios, which combine different parameters values and significance levels. Each day we compute these PMs for each individual stock using the last 264 daily returns, sort the stocks by each PM, and select the best 20 to be included in a portfolio. The first result is that the selected stocks for different PMs can be very different. The percentage of coincident assets is low when comparing the Generalized Rachev or the VaR ratios selections with the other PMs and especially with the Sharpe ratio.

Second, we compute the next day (OOS) return that each portfolio generates. Descriptive statistics for the entire OOS period indicate that the portfolios based on the VaR ratio at 5\% level and the Generalized Rachev at 1\% level show not only the highest mean return (around 350\% and 200\% higher than the mean return on the Sharpe based portfolio, respectively), but also the highest values for different mean-risk ratios including the Sharpe ratio. This result states how important differences between in-sample and out-of-sample returns can be. In addition, these portfolios show the lowest correlation with the Sharpe-based portfolio which is especially low (even negative) during the crisis period. Finally, we compute cumulative OOS returns and find, generally, positive differences between most portfolios and the Sharpe-based one. A stochastic dominance analysis shows that effectively the Sharpe portfolio returns are dominated by most others. The remarkable case is the portfolio based on Generalized Rachev measure with 1\% level. This portfolio displays the largest spread in cumulative 
returns regarding the Sharpe one (around 200\% on average), and it dominates not only the Sharpe returns but also the other portfolios.

The final part of the paper analyzes the statistical and economic characteristics of the stocks selected by the different PMs in order to understand the best OOS performance of the Generalized Rachev selected stocks. Working with the in-sample individual returns, we first compute rolling moments for the stocks selected by each PM and find that, unlike the Sharpe selected stocks, the GR ones show high kurtosis and positive skewness. Lastly, we estimate an asset pricing model that includes a huge set of well-known systematic risk factors. Results indicate that the risk exposition of the returns on stocks selected different PMs is clearly different. All portfolios with the exception of those formed with stocks selected by Generalized Rachev or VaR ratios show similar betas. In addition to the market risk, they are positively exposed to the size and momentum factors, and negatively exposed to the investment factor. It must be point out that the intensity of the risk exposure depends on the parameters values in the case of the portfolios selected by Farinelly-Tibeletti. In contrast, Generalized Rachev or VaR based portfolios are insensitive to the momentum factor. This factor is characterized by high levels of kurtosis and negative skewness and then it is largely affected by the negative shock occurred in 2008. Therefore, this result indicates that stocks selected by PMs based on quantiles suffer a relatively lower negative impact because of the market crisis and then their recovery can be (and in fact is) quicker. This is confirmed by the small or even negative correlation between rolling skewness for these stock returns and the momentum factor. Additionally, if we impose a $1 \%$ level in the Generalized Rachev, returns on the resulting selection show zero exposure to any other type of risk different from the market.

Summarizing, on the one hand, the general conclusion of this work is that different PMs can produce both different rankings and different OOS returns. On the other hand, the distributional properties of returns (which are used to select stocks under different PMs) are connected with the 
economic fundamentals of asset pricing. We find that if we focus on the probabilistic mass on the tails of the distribution by searching for a higher mass in the right tail allows finding stocks uncorrelated with a multitude of risks types. This property is especially relevant in recession periods.

\section{Acknowledgements}

This work was supported by the Generalitat Valenciana (PROMETEO/2017/158), the Spanish Department of Economy and Competitiveness (ECO2015-67035-P and ECO2017-87069-P), and the Bank of Spain (Excellence in Education and Research Grant 2016). We thank Enrique Sentana for his helpful discussion in the XXIII Finance Forum at the Universidad Pontificia de Comillas in Madrid, and seminar participants at the Universidad CEU San Pablo in Elche and CUNEF in Madrid for useful comments on the paper. We assume full responsibility for any remaining errors.

\section{References}

Amaya, D., Christoffersen, P., Jacobs, K., Vasquez, A., 2015. Does realized skewness predict the crosssection of equity returns? Journal of Financial Economics 118, 135-167. DOI: 10.1016/j.jfineco.2015.02.009.

Ang, A., 2014. Asset Management: A Systematic Approach to Factor Investing, Oxford University Press, New York.

Asness, C., Frazzini, A., Pedersen, L.H., 2017. Quality minus junk, SSRN working paper. https://papers.ssrn.com/sol3/papers.cfm?abstract id=2312432

Bacon, C.R., 2008. Practical Portfolio Performance Measurement and Attribution, second edition, Wiley, New York.

Bernardo, A.E., Ledoit, O., 2000. Gain, Loss and Asset Pricing, Journal of Political Economy 108(1), 144 172. DOI: $10.1086 / 262114$

Biglova, A., Ortobelli, S., Rachev, S., Stoyanov, S., 2004. Different Approaches to Risk Estimation in Portfolio Theory, Journal of Portfolio Management 31(1), 103-112. DOI: 10.3905/jpm.2004.443328.

Billio, M., Caporin, M., Costola, M., 2015. Backward/forward optimal combination of performance measures for equity screening, North American Journal of Economics and Finance 34, 63-83.

Caporin, M., Jannin, G.M., Lisi F., Maillet, B.B., 2014. A survey on the four families of performance measures, Journal of Economic Surveys 28(5), 917-942. DOI:10.1111/joes.12041.

Caporin, M., Lisi, F., 2011. Comparing and Selecting Performance Measures Using Rank Correlations, Economics: The Open-Access, Open-Assessment E-Journal 5, 1-34. DOI: 10.5018/economicsejournal.ja.2011-10.

Davidson, R., Duclos, J.Y., 2000. Statistical inference for stochastic dominance and for the measurement of poverty and inequality, Econometrica 68(6), 1435-1464.

De Miguel, V., Garlappi, L., Uppal, R., 2009. Optimal versus naïve diversification: How inefficient is the $1 / \mathrm{N}$ portfolio strategy, The Review of Financial Studies 22, 1915-1953. DOI: $10.1093 / \mathrm{rfs} / \mathrm{hhm} 075$. 
Eling, M., 2008. Does the measure matter in the mutual fund industry?, Financial Analysts Journal 64(3), 54-66. DOI: 10.2469/ faj.v64.n3.6.

Eling, M., Schuhmacher, F., 2007. Does the choice of performance measure influence the evaluation of hedge funds?, Journal of Banking \& Finance 31, 2632-2647. DOI: 10.1016/j.jbankfin.2006.09.015.

Engle, R.F., 2002. Dynamic conditional correlation: A simple class of multivariate generalized autoregressive conditional heteroscedasticity models, Journal of Business \& Economic Statistics 20, 339-50. DOI: 10.1198/073500102288618487.

Fama, E., French, K., 2015. A five-factor asset pricing model, Journal of Financial Economics 116, 1-22. DOI: $10.106 /$ j.jfineco.2014.10.010

Farinelli, S., Ferreira, M., Rossello, D., Thoeny, M., Tibiletti, L., 2009. Optimal asset allocation aid system: From "one-size" vs "tailor-made" performance ratio, European Journal of Operational Research 192, 209-215. DOI: 10.1016/j.ejor.2007.08.035.

Farinelli, S., Tibiletti, L., 2008. Sharpe thinking in asset ranking with one-sided measures, European Journal of Operational Research 185, 1542-1547. DOI: 10.1016/j.ejor.2006.08.020.

Fishburn, P.C., 1977. Mean-risk analysis with risk associated with below-target returns, American Economic Review 67(2), 116-126.

Guo, B., Xiao, Y., 2016. A note on why doesn't the choice of the performance measure matter? Finance Research Letters 16, 248-254. DOI: 10.1016/j.frl.2015.12.001.

Jain, P.C., 1987. The effect on stock price of inclusion in or exclusion from the S\&P 500, Financial Analysts Journal 43, 58-65.

Kaplan, P.D., Knowles, J.A., 2004. Kappa: A generalized downside risk-adjusted performance measure, Journal of Performance Measurement 8(3), 42-54.

Keating, C., Shadwick, W.F., 2002. A universal performance measure, Journal of Performance Measurement 6(3), 59-84.

Konno, H., Yamazaki, H., 1991. Mean-absolute deviation portfolio optimization model and its application to Tokyo stock market, Management Science 37, 519-531.

León, A., Moreno, M., 2017. One-sided performance measures under Gram-Charlier distributions. Journal of Banking and Finance 74, 38-50. DOI: 10.1016/j.jbankfin.2016.10.005

Magron, C., 2014. Are individual investors such poor portfolio managers?, Docplayer working paper, http://docplayer.net/319631-Are-individual-investors-such-poor-portfolio-managers.html

Pézier, J., White, A., 2008. The relative merits of alternative investments in passive portfolios, Journal of Alternative Investments 10(4), 37-49. DOI: 10.3905/jai.2008.705531.

Pruitt, S., Wei, K.C.J., 1989. Institutional ownership and changes in the S\&P 500, Journal of Finance 44, 509-513. DOI: $10.2307 / 2328603$.

Rehman, Z., Vilkov, G., 2012. Risk-neutral skewness: return predictability and its sources, SSRN working paper. https://papers.ssrn.com/sol3/papers.cfm?abstract id=1301648

Sharpe, W.F., 1966. Mutual fund performance, Journal of Business 39, 119-138.

Sharpe, W.F., 1994. The Sharpe ratio, Journal of Portfolio Management 21, 49-58. DOI: 10.3905/jpm.1994.409501.

Sortino, F.A., Satchell, S., 2001. Managing Downside Risk in Financial Markets: Theory, Practice and Implementation, Butterworth Heinemann, Oxford.

Sortino, F.A., van der Meer, R., 1991. Downside risk, Journal of Portfolio Management 17(4), 27-31. DOI: 10.3905/jpm.1991.409343.

Sortino, F.A., van der Meer, R., Platinga, A., 1999. The Dutch triangle, Journal of Portfolio Management 26, 50-57. DOI: 10.3905/jpm.1999.319775. 
Stoline, M.R., Ury, H.K., 1979. Tables of the studentized maximum modulus distribution and an application to multiple comparisons among means, Technometrics 21, 87-93.

Xing, Y., Zhang, X., Zhao, R., 2010. What does the individual option volatility smirk tell us about future equity returns? Journal of Financial and Quantitative Analysis 45, 641-662. DOI: $10.1017 /$ S0022109010000220.

Young, M.R., 1998. A minimax portfolio selection rule with linear programming solution, Management Science 44, 673-683.

Zakamouline, V., 2011. The performance measure you choose influences the evaluation of hedge funds, Journal of Performance Measurement 15(3), 48-64. 
Table 1. Percentage of coincident assets comparing pairs of portfolios based on different measures. Median values.

\begin{tabular}{|c|c|c|c|c|c|c|c|c|c|c|c|c|c|c|c|c|c|c|c|c|c|c|c|c|c|c|c|c|c|c|c|}
\hline & $\overline{\mathrm{ASR}}$ & & & & & & & & & & $\mathrm{T}$ & & & & & & & & & VaRR5 & & & & & & & VaRR1 & MAD & MM & Range & Gini \\
\hline & 2 & 3 & 4 & 5 & 6 & 7 & 8 & 9 & 10 & 11 & 12 & 13 & 14 & 15 & 16 & 17 & 18 & 19 & 20 & 21 & 22 & 23 & 24 & 25 & 26 & 27 & 28 & 29 & 30 & 31 & 32 \\
\hline 1 & 100 & 75 & 85 & 90 & 90 & 90 & 85 & 75 & 50 & 90 & 35 & 25 & 65 & 20 & 25 & 20 & 25 & 25 & 20 & 25 & 15 & 15 & 15 & 15 & 15 & 15 & 15 & 90 & 60 & 70 & 95 \\
\hline 2 & & 75 & 90 & 90 & 90 & 90 & 85 & 75 & 50 & 90 & 35 & 25 & 70 & 25 & 25 & 25 & 25 & 25 & 25 & 25 & 20 & 20 & 20 & 20 & 20 & 20 & 15 & 90 & 60 & 70 & 95 \\
\hline 3 & & & 85 & 75 & 75 & 70 & 65 & 70 & 60 & 70 & 40 & 25 & 80 & 25 & 30 & 30 & 30 & 35 & 30 & 20 & 25 & 25 & 25 & 25 & 25 & 25 & 20 & 70 & 55 & 70 & $\begin{array}{l}70 \\
\end{array}$ \\
\hline 4 & & & & 95 & 90 & 85 & 80 & 70 & 60 & 85 & 45 & 30 & 80 & 30 & 35 & 30 & 30 & 35 & 30 & 25 & 25 & 25 & 25 & 25 & 25 & 25 & 20 & 85 & 55 & 65 & 85 \\
\hline 5 & & & & & 95 & 90 & 85 & 70 & 60 & 90 & 45 & 35 & 75 & 30 & 30 & 30 & 30 & 30 & 30 & 25 & 25 & 25 & 25 & 25 & 25 & 25 & 20 & 90 & 55 & 65 & 90 \\
\hline 6 & & & & & & 95 & 90 & 65 & 55 & 95 & 45 & 35 & 70 & 30 & 30 & 30 & 30 & 30 & 30 & 25 & 25 & 25 & 25 & 25 & 25 & 25 & 20 & 95 & 55 & 60 & 95 \\
\hline 7 & & & & & & & 95 & 65 & 50 & 100 & 40 & 35 & 65 & 25 & 30 & 25 & 30 & 25 & 25 & 25 & 20 & 20 & 20 & 20 & 20 & 20 & 20 & 100 & 50 & 60 & 95 \\
\hline 8 & & & & & & & & 65 & 50 & 90 & 40 & 35 & 60 & 25 & 25 & 25 & 25 & 25 & 25 & 20 & 20 & 20 & 20 & 20 & 20 & 20 & 20 & 95 & 50 & 60 & 90 \\
\hline 9 & & & & & & & & & 45 & 65 & 25 & 20 & 70 & 15 & 20 & 20 & 20 & 20 & 20 & 15 & 15 & 15 & 15 & 15 & 15 & 15 & 10 & 65 & 60 & 70 & 70 \\
\hline 10 & & & & & & & & & & 55 & 70 & 40 & 70 & 60 & 60 & 60 & 60 & 60 & 60 & 30 & 50 & 50 & 50 & 50 & 50 & 50 & 35 & 55 & 25 & 35 & 55 \\
\hline 11 & & & & & & & & & & & 45 & 35 & 65 & 30 & 30 & 30 & 30 & 30 & 30 & 25 & 25 & 25 & 20 & 25 & 25 & 20 & 20 & 100 & 50 & 60 & 95 \\
\hline 12 & & & & & & & & & & & & 65 & 45 & 65 & 55 & 60 & 60 & 50 & 65 & 25 & 65 & 60 & 60 & 60 & 55 & 60 & 40 & 40 & 10 & 15 & 40 \\
\hline 13 & & & & & & & & & & & & & 25 & 45 & 35 & 40 & 35 & 25 & 40 & 15 & 50 & 45 & 45 & 45 & 40 & 45 & 30 & 35 & 5 & 10 & 30 \\
\hline 14 & & & & & & & & & & & & & & 35 & 40 & 40 & 40 & 40 & 40 & 30 & 30 & 30 & 30 & 30 & 30 & 30 & 25 & 65 & 50 & 55 & 65 \\
\hline 15 & & & & & & & & & & & & & & & 85 & 90 & 90 & 75 & 90 & 30 & 60 & 60 & 60 & 60 & 60 & 60 & 55 & 30 & 5 & 10 & 25 \\
\hline 16 & & & & & & & & & & & & & & & & 95 & 90 & 90 & 90 & 30 & 60 & 60 & 60 & 60 & 60 & 60 & 50 & 30 & 10 & 15 & 30 \\
\hline 17 & & & & & & & & & & & & & & & & & 90 & 85 & 95 & 25 & 65 & 65 & 65 & 65 & 65 & 65 & 50 & 30 & 5 & 10 & 25 \\
\hline 18 & & & & & & & & & & & & & & & & & & 85 & 85 & 30 & 60 & 55 & 55 & 55 & 60 & 55 & 50 & 30 & 10 & 15 & 30 \\
\hline 19 & & & & & & & & & & & & & & & & & & & 80 & 30 & 50 & 55 & 50 & 55 & 55 & 50 & 50 & 30 & 10 & 15 & 30 \\
\hline 20 & & & & & & & & & & & & & & & & & & & & 25 & 70 & 70 & 70 & 70 & 70 & 70 & 50 & 25 & 5 & 10 & 25 \\
\hline 21 & & & & & & & & & & & & & & & & & & & & & 10 & 10 & 10 & 10 & 10 & 10 & 15 & 25 & 15 & 20 & 25 \\
\hline 22 & & & & & & & & & & & & & & & & & & & & & & 95 & 95 & 95 & 90 & 95 & 45 & 25 & 0 & 5 & 20 \\
\hline 23 & & & & & & & & & & & & & & & & & & & & & & & 95 & 100 & 95 & 95 & 50 & 20 & 0 & 5 & 20 \\
\hline 24 & & & & & & & & & & & & & & & & & & & & & & & & 95 & 90 & 100 & 45 & 20 & 0 & 5 & 20 \\
\hline 25 & & & & & & & & & & & & & & & & & & & & & & & & & 95 & 95 & 45 & 20 & 0 & 5 & 20 \\
\hline 26 & & & & & & & & & & & & & & & & & & & & & & & & & & 90 & 50 & 20 & 0 & 5 & 20 \\
\hline 27 & & & & & & & & & & & & & & & & & & & & & & & & & & & 45 & 20 & 0 & 5 & 20 \\
\hline 28 & & & & & & & & & & & & & & & & & & & & & & & & & & & & 20 & 5 & 10 & 20 \\
\hline 29 & & & & & & & & & & & & & & & & & & & & & & & & & & & & & 50 & 60 & 95 \\
\hline 30 & & & & & & & & & & & & & & & & & & & & & & & & & & & & & & 85 & 55 \\
\hline 31 & & & & & & & & & & & & & & & & & & & & & & & & & & & & & & & 65 \\
\hline
\end{tabular}

Measures 1 and 2 are the Sharpe and adjusted Sharpe (ASR) ratios, respectively. Measures 3 to 8 are the kappa ratios (SS) with the following values for the parameters: 10, 3, 2, 1.5, 0.8, and 0.5. Measures 9 to 14 are the Farinelli-Tibiletti ratios (FT) with the following pair of values for the parameters: (0.5, 2), (1.5, 2), (1, 1), (2, 1.5), (3, $0.5)$, and $(1,2)$. Measures 15 to 20 and 22 to 27 are the generalized Rachev ratios (GR) evaluated at the 5\% and 1\% levels, respectively. In both cases, the values for each pair of parameters are $(0.8,0.001),(0.5,0.8),(0.8,0.8),(0.5,1),(0.01,0.8)$, and $(1,1)$. Measures 21 and 28 are the VaR ratios at the $5 \%$ and $1 \%$ levels, respectively; measures 29 and 30 are ratios that employ the mean absolute deviation (MAD) and the distance between the maximum and the minimum (MM) as the measure of risk, respectively; measure 31 is the Range ratio, which employs the absolute value of the distance between the maximum and the minimum; and measure 32 is the mean-Gini ratio. 
Table 2

Descriptive statistics of out-of-sample portfolio returns.

\begin{tabular}{|c|c|c|c|c|c|c|c|c|c|c|c|c|}
\hline & SR & ASR & SS & FT & GR5 & VaRR5 & GR1 & VaRR1 & MAD & $\mathrm{MM}$ & Range & Gini \\
\hline Mean & 0.0033 & 0.0058 & 0.0040 & 0.0057 & 0.0029 & 0.0146 & 0.0096 & 0.0031 & 0.0062 & 0.0075 & 0.0025 & 0.0073 \\
\hline $\operatorname{Max}$ & 7.756 & 7.756 & 7.756 & 8.429 & 9.863 & 10.302 & 9.693 & 10.298 & 7.756 & 7.756 & 7.756 & 7.756 \\
\hline Min & -9.934 & -9.934 & -9.983 & -10.951 & -11.804 & -11.706 & -9.709 & -9.801 & -9.934 & -9.758 & -9.758 & -9.934 \\
\hline $\mathrm{StD}$ & 1.424 & 1.425 & 1.409 & 1.383 & 1.442 & 1.524 & 1.407 & 1.390 & 1.409 & 1.457 & 1.462 & 1.416 \\
\hline Beta & 0.953 & 0.952 & 0.957 & 1.063 & 1.095 & 1.170 & 1.101 & 1.144 & 0.934 & 0.997 & 1.019 & 0.941 \\
\hline Skewness & -0.549 & -0.554 & -0.597 & -0.701 & -0.773 & -0.660 & -0.489 & -0.597 & -0.556 & -0.722 & -0.736 & -0.561 \\
\hline Exc.Kurtosis & 4.389 & 4.391 & 4.664 & 6.517 & 7.888 & 7.308 & 6.286 & 7.104 & 4.474 & 5.092 & 5.070 & 4.473 \\
\hline $\operatorname{VaR}(1 \%)$ & 0.041 & 0.042 & 0.041 & 0.041 & 0.042 & 0.049 & 0.040 & 0.041 & 0.041 & 0.045 & 0.045 & 0.042 \\
\hline $\operatorname{VaR}(5 \%)$ & 0.024 & 0.024 & 0.024 & 0.022 & 0.022 & 0.025 & 0.023 & 0.022 & 0.024 & 0.025 & 0.025 & 0.024 \\
\hline $\operatorname{CVaR}(1 \%)$ & 0.056 & 0.056 & 0.056 & 0.058 & 0.064 & 0.068 & 0.058 & 0.060 & 0.056 & 0.060 & 0.061 & 0.056 \\
\hline $\operatorname{CVaR}(5 \%)$ & 0.036 & 0.037 & 0.036 & 0.035 & 0.036 & 0.039 & 0.035 & 0.035 & 0.036 & 0.038 & 0.038 & 0.036 \\
\hline Correlations & & ASR & SS & FT & GR5 & VaRR5 & GR1 & VaRR1 & MAD & $\mathrm{MM}$ & Range & Gini \\
\hline SR & & 0.999 & 0.995 & 0.964 & 0.831 & 0.835 & 0.813 & 0.803 & 0.992 & 0.969 & 0.976 & 0.994 \\
\hline ASR & & & 0.995 & 0.965 & 0.833 & 0.836 & 0.816 & 0.805 & 0.993 & 0.968 & 0.975 & 0.995 \\
\hline SS & & & & 0.974 & 0.849 & 0.846 & 0.831 & 0.818 & 0.997 & 0.965 & 0.973 & 0.997 \\
\hline FT & & & & & 0.923 & 0.910 & 0.908 & 0.892 & 0.970 & 0.936 & 0.942 & 0.969 \\
\hline GR5 & & & & & & 0.928 & 0.964 & 0.953 & 0.845 & 0.799 & 0.806 & 0.841 \\
\hline VaRR5 & & & & & & & 0.894 & 0.895 & 0.843 & 0.814 & 0.816 & 0.841 \\
\hline GR1 & & & & & & & & 0.949 & 0.828 & 0.782 & 0.787 & 0.824 \\
\hline VaRR1 & & & & & & & & & 0.815 & 0.777 & 0.781 & 0.812 \\
\hline MAD & & & & & & & & & & 0.959 & 0.966 & 0.997 \\
\hline MM & & & & & & & & & & & 0.992 & 0.962 \\
\hline Range & & & & & & & & & & & & 0.969 \\
\hline
\end{tabular}

This table presents descriptive statistics for the daily portfolio returns for the entire OOS period, January 2006 to September 2014 . The portfolios are constructed by equally weighting the 20 stocks selected on the basis of a pre-ranking that uses different performance measures: SR and ASR are the standard and adjusted Sharpe ratios, respectively; SS represents Sortino-Satchell ratios; FT represents the Farinelli-Tibiletti ratios; GR1 and GR5 are the generalized Rachev ratios with 1 percent and 5 percent confidence levels, respectively; VaRR1 and VaRR 5 are the value at risk at the 1 percent and 5 percent confidence levels; and the MAD, MM, Range, and Gini measures are risk-reward ratios that employ the mean absolute deviation, the distance between the maximum and the minimum, the absolute distance between the maximum and minimum, and the Shalit-Yitzhaki difference, respectively, as the risk measure. Panel A provides standard return statistics, namely, the mean, maximum, minimum, standard deviation, market beta (Beta), skewness, and excess kurtosis and the value at risk $(\mathrm{VaR})$ and conditional value at risk $(\mathrm{CVaR})$ at the 1 percent and 5 percent levels. Panel $\mathrm{B}$ displays the sample correlation between pairs of portfolio returns. 
Table 3

Stochastic dominance: Equally weighted portfolios with daily rebalancing.

Panel A: First order

\begin{tabular}{|c|c|c|c|c|c|c|c|c|c|c|c|c|}
\hline & & ASR & SS & FT & GR5 & VaRR5 & GR1 & VaRR1 & MAD & MM & Range & Gini \\
\hline$\overline{\mathrm{SR}}$ & $\begin{array}{l}\text { DD+ } \\
\text { DD- }\end{array}$ & $\begin{array}{c}61 \\
7\end{array}$ & $\begin{array}{l}11 \\
65\end{array}$ & $\begin{array}{l}52 \\
16\end{array}$ & $\begin{array}{c}67 \\
6\end{array}$ & $\begin{array}{c}93 \\
0\end{array}$ & $\begin{array}{c}96 \\
0\end{array}$ & $\begin{array}{l}28 \\
34\end{array}$ & $\begin{array}{l}58 \\
16\end{array}$ & $\begin{array}{c}94 \\
0\end{array}$ & $\begin{array}{c}5 \\
66\end{array}$ & $\begin{array}{c}68 \\
2\end{array}$ \\
\hline$\overline{\mathrm{ASR}}$ & $\begin{array}{l}\text { DD+ } \\
\text { DD- }\end{array}$ & & $\begin{array}{c}0 \\
86\end{array}$ & $\begin{array}{l}21 \\
32 \\
\end{array}$ & $\begin{array}{l}46 \\
18 \\
\end{array}$ & $\begin{array}{c}93 \\
0\end{array}$ & $\begin{array}{c}96 \\
0\end{array}$ & $\begin{array}{l}21 \\
44 \\
\end{array}$ & $\begin{array}{l}26 \\
12 \\
\end{array}$ & $\begin{array}{c}73 \\
2 \\
\end{array}$ & $\begin{array}{c}0 \\
66 \\
\end{array}$ & $\begin{array}{c}71 \\
0 \\
\end{array}$ \\
\hline$\overline{\mathrm{SS}}$ & $\begin{array}{l}\text { DD+ } \\
\text { DD- }\end{array}$ & & & $\begin{array}{c}84 \\
0\end{array}$ & $\begin{array}{c}72 \\
4\end{array}$ & $\begin{array}{c}95 \\
0\end{array}$ & $\begin{array}{c}96 \\
0\end{array}$ & $\begin{array}{l}58 \\
13\end{array}$ & $\begin{array}{c}92 \\
0\end{array}$ & $\begin{array}{c}94 \\
0\end{array}$ & $\begin{array}{l}28 \\
34 \\
\end{array}$ & $\begin{array}{c}92 \\
0\end{array}$ \\
\hline FT & $\begin{array}{l}\text { DD+ } \\
\text { DD- }\end{array}$ & & & & $\begin{array}{l}44 \\
25 \\
\end{array}$ & $\begin{array}{c}94 \\
0\end{array}$ & $\begin{array}{c}94 \\
0\end{array}$ & $\begin{array}{l}24 \\
32 \\
\end{array}$ & $\begin{array}{l}26 \\
20 \\
\end{array}$ & $\begin{array}{c}81 \\
0 \\
\end{array}$ & $\begin{array}{l}13 \\
73 \\
\end{array}$ & $\begin{array}{l}59 \\
10 \\
\end{array}$ \\
\hline$\overline{\text { GR5 }}$ & $\begin{array}{l}\text { DD+ } \\
\text { DD- }\end{array}$ & & & & & $\begin{array}{c}90 \\
0\end{array}$ & $\begin{array}{c}92 \\
0\end{array}$ & $\begin{array}{l}26 \\
55 \\
\end{array}$ & $\begin{array}{l}20 \\
42 \\
\end{array}$ & $\begin{array}{c}78 \\
0 \\
\end{array}$ & $\begin{array}{c}0 \\
79 \\
\end{array}$ & $\begin{array}{l}32 \\
20 \\
\end{array}$ \\
\hline VaRR5 & $\begin{array}{l}\text { DD+ } \\
\text { DD- }\end{array}$ & & & & & & $\begin{array}{l}62 \\
25\end{array}$ & $\begin{array}{c}0 \\
93\end{array}$ & $\begin{array}{c}0 \\
94\end{array}$ & $\begin{array}{l}12 \\
78\end{array}$ & $\begin{array}{c}0 \\
93\end{array}$ & $\begin{array}{c}0 \\
88\end{array}$ \\
\hline$\overline{\text { GR1 }}$ & $\begin{array}{l}\text { DD+ } \\
\text { DD- }\end{array}$ & & & & & & & $\begin{array}{c}0 \\
92\end{array}$ & $\begin{array}{c}0 \\
96\end{array}$ & $\begin{array}{c}0 \\
89\end{array}$ & $\begin{array}{c}0 \\
96 \\
\end{array}$ & $\begin{array}{c}0 \\
96 \\
\end{array}$ \\
\hline VaRR1 & $\begin{array}{l}\text { DD+ } \\
\text { DD- }\end{array}$ & & & & & & & & $\begin{array}{l}48 \\
23 \\
\end{array}$ & $\begin{array}{c}78 \\
0 \\
\end{array}$ & $\begin{array}{l}11 \\
60 \\
\end{array}$ & $\begin{array}{l}60 \\
15 \\
\end{array}$ \\
\hline$\overline{\mathrm{MAD}}$ & $\begin{array}{l}\text { DD+ } \\
\text { DD- }\end{array}$ & & & & & & & & & $\begin{array}{c}72 \\
2 \\
\end{array}$ & $\begin{array}{c}8 \\
67 \\
\end{array}$ & $\begin{array}{c}79 \\
0 \\
\end{array}$ \\
\hline$\overline{\mathrm{MM}}$ & $\begin{array}{l}\text { DD+ } \\
\text { DD- }\end{array}$ & & & & & & & & & & $\begin{array}{c}0 \\
94\end{array}$ & $\begin{array}{l}17 \\
59\end{array}$ \\
\hline Range & $\begin{array}{l}\text { DD+ } \\
\text { DD- }\end{array}$ & & & & & & & & & & & $\begin{array}{c}77 \\
0 \\
\end{array}$ \\
\hline \multicolumn{13}{|c|}{ Panel B: Second order } \\
\hline & & ASR & SS & FT & GR5 & VaRR5 & GR1 & VaRR1 & MAD & MM & Range & Gini \\
\hline$\overline{\mathrm{SR}}$ & $\begin{array}{l}\text { DD+ } \\
\text { DD- }\end{array}$ & $\begin{array}{l}51 \\
40 \\
\end{array}$ & $\begin{array}{c}0 \\
95\end{array}$ & $\begin{array}{l}39 \\
43 \\
\end{array}$ & $\begin{array}{l}74 \\
7 \\
\end{array}$ & $\begin{array}{c}93 \\
0 \\
\end{array}$ & $\begin{array}{c}96 \\
0 \\
\end{array}$ & $\begin{array}{l}16 \\
69 \\
\end{array}$ & $\begin{array}{l}46 \\
45 \\
\end{array}$ & $\begin{array}{c}95 \\
0 \\
\end{array}$ & $\begin{array}{c}0 \\
95 \\
\end{array}$ & $\begin{array}{l}65 \\
28 \\
\end{array}$ \\
\hline$\overline{\mathrm{ASR}}$ & $\begin{array}{l}\text { DD+ } \\
\text { DD- }\end{array}$ & & $\begin{array}{c}0 \\
96 \\
\end{array}$ & $\begin{array}{c}6 \\
72 \\
\end{array}$ & $\begin{array}{c}56 \\
5 \\
\end{array}$ & $\begin{array}{c}94 \\
0\end{array}$ & $\begin{array}{c}96 \\
0\end{array}$ & $\begin{array}{c}0 \\
66 \\
\end{array}$ & $\begin{array}{l}17 \\
64 \\
\end{array}$ & $\begin{array}{c}96 \\
0\end{array}$ & $\begin{array}{c}0 \\
90 \\
\end{array}$ & $\begin{array}{c}82 \\
4 \\
\end{array}$ \\
\hline$\overline{\mathrm{SS}}$ & $\begin{array}{l}\text { DD+ } \\
\text { DD- }\end{array}$ & & & $\begin{array}{c}84 \\
4 \\
\end{array}$ & $\begin{array}{c}87 \\
0\end{array}$ & $\begin{array}{c}96 \\
0\end{array}$ & $\begin{array}{c}96 \\
0\end{array}$ & $\begin{array}{c}77 \\
7 \\
\end{array}$ & $\begin{array}{c}96 \\
0\end{array}$ & $\begin{array}{c}96 \\
0 \\
\end{array}$ & $\begin{array}{l}56 \\
36 \\
\end{array}$ & $\begin{array}{c}96 \\
0\end{array}$ \\
\hline$\overline{\mathrm{FT}}$ & $\begin{array}{l}\text { DD+ } \\
\text { DD- }\end{array}$ & & & & $\begin{array}{c}84 \\
0 \\
\end{array}$ & $\begin{array}{c}93 \\
0 \\
\end{array}$ & $\begin{array}{c}92 \\
0 \\
\end{array}$ & $\begin{array}{c}0 \\
59 \\
\end{array}$ & $\begin{array}{c}29 \\
0 \\
\end{array}$ & $\begin{array}{c}92 \\
0 \\
\end{array}$ & $\begin{array}{l}22 \\
62 \\
\end{array}$ & $\begin{array}{c}92 \\
0 \\
\end{array}$ \\
\hline$\overline{\text { GR5 }}$ & $\begin{array}{l}\text { DD+ } \\
\text { DD- }\end{array}$ & & & & & $\begin{array}{c}92 \\
0 \\
\end{array}$ & $\begin{array}{c}91 \\
0 \\
\end{array}$ & $\begin{array}{c}0 \\
91 \\
\end{array}$ & $\begin{array}{c}0 \\
54 \\
\end{array}$ & $\begin{array}{c}91 \\
0 \\
\end{array}$ & $\begin{array}{c}5 \\
79 \\
\end{array}$ & $\begin{array}{l}42 \\
35 \\
\end{array}$ \\
\hline VaRR5 & $\begin{array}{l}\text { DD+ } \\
\text { DD- }\end{array}$ & & & & & & $\begin{array}{c}92 \\
0 \\
\end{array}$ & $\begin{array}{c}0 \\
91 \\
\end{array}$ & $\begin{array}{c}0 \\
95 \\
\end{array}$ & $\begin{array}{l}18 \\
66 \\
\end{array}$ & $\begin{array}{c}0 \\
94 \\
\end{array}$ & $\begin{array}{c}0 \\
94 \\
\end{array}$ \\
\hline$\overline{\text { GR1 }}$ & $\begin{array}{l}\text { DD+ } \\
\text { DD- }\end{array}$ & & & & & & & $\begin{array}{c}0 \\
91 \\
\end{array}$ & $\begin{array}{c}0 \\
96 \\
\end{array}$ & $\begin{array}{c}0 \\
88 \\
\end{array}$ & $\begin{array}{c}0 \\
96\end{array}$ & $\begin{array}{c}0 \\
95 \\
\end{array}$ \\
\hline VaRR1 & $\begin{array}{l}\text { DD+ } \\
\text { DD- }\end{array}$ & & & & & & & & $\begin{array}{c}53 \\
0 \\
\end{array}$ & $\begin{array}{c}91 \\
0 \\
\end{array}$ & $\begin{array}{l}15 \\
49 \\
\end{array}$ & $\begin{array}{c}82 \\
0 \\
\end{array}$ \\
\hline$\overline{\mathrm{MAD}}$ & $\begin{array}{l}\text { DD+ } \\
\text { DD- }\end{array}$ & & & & & & & & & $\begin{array}{c}95 \\
0 \\
\end{array}$ & $\begin{array}{l}22 \\
68 \\
\end{array}$ & $\begin{array}{c}97 \\
0 \\
\end{array}$ \\
\hline MM & $\begin{array}{l}\mathrm{DD}+ \\
\mathrm{DD}-\end{array}$ & & & & & & & & & & $\begin{array}{c}0 \\
95 \\
\end{array}$ & $\begin{array}{c}0 \\
95 \\
\end{array}$ \\
\hline Range & $\begin{array}{l}\mathrm{DD}+ \\
\mathrm{DD}-\end{array}$ & & & & & & & & & & & $\begin{array}{c}88 \\
0 \\
\end{array}$ \\
\hline
\end{tabular}

This table displays the results for the stochastic dominance comparison between cumulative returns on pairs of equally weighted portfolios. First- and second-order stochastic dominance results are provided in panels A and B, respectively. The stocks included in each portfolio were selected using the specific performance measure indicated in the first row. See Table 2 for the definitions. The returns are daily for the period between January 2006 and September 2014. DD+ (DD-) refers to the percentage of Davidson-Duclos (2000) significant positive (negative) test statistics. See Section 4.4 for details. 
Table 4

Stochastic dominance: Equally weighted portfolios with monthly rebalancing.

\begin{tabular}{|c|c|c|c|c|c|c|c|c|c|c|c|c|}
\hline \multicolumn{13}{|c|}{ Panel A: First order } \\
\hline & & ASR & SS & FT & GR5 & VaRR5 & GR1 & VaRR1 & MAD & MM & Range & Gini \\
\hline \multirow[t]{2}{*}{$\overline{\mathrm{SR}}$} & $\mathrm{DD}+$ & 59 & 90 & 88 & 71 & 76 & 96 & 61 & 22 & 47 & 96 & 91 \\
\hline & DD- & 0 & 0 & 0 & 6 & 12 & 0 & 7 & 38 & 0 & 0 & 0 \\
\hline \multirow{2}{*}{$\overline{\mathrm{ASR}}$} & $\mathrm{DD}+$ & & 65 & 87 & 53 & 71 & 96 & 41 & 14 & 42 & 96 & 82 \\
\hline & DD- & & 0 & 0 & 14 & 12 & 0 & 12 & 55 & 33 & 0 & 0 \\
\hline \multirow{2}{*}{$\overline{\mathrm{SS}}$} & $\mathrm{DD}+$ & & & 77 & 31 & 69 & 95 & 27 & 0 & 40 & 96 & 28 \\
\hline & DD- & & & 0 & 27 & 16 & 0 & 23 & 82 & 47 & 0 & 5 \\
\hline \multirow[t]{2}{*}{$\overline{\mathrm{FT}}$} & $\mathrm{DD}+$ & & & & 0 & 31 & 93 & 0 & 0 & 19 & 93 & 0 \\
\hline & DD- & & & & 67 & 47 & 0 & 64 & 86 & 56 & 0 & 76 \\
\hline \multirow[t]{2}{*}{$\overline{\text { GR5 }}$} & $\mathrm{DD}+$ & & & & & 44 & 93 & 28 & 9 & 33 & 92 & 27 \\
\hline & DD- & & & & & 23 & 0 & 35 & 66 & 42 & 0 & 25 \\
\hline \multirow{2}{*}{$\overline{\text { VaRR5 }}$} & $\mathrm{DD}+$ & & & & & & 95 & 13 & 13 & 32 & 64 & 18 \\
\hline & DD- & & & & & & 0 & 54 & 70 & 50 & 17 & 59 \\
\hline \multirow[t]{2}{*}{$\overline{\text { GR1 }}$} & $\mathrm{DD}+$ & & & & & & & 0 & 0 & 0 & 0 & 0 \\
\hline & DD- & & & & & & & 92 & 95 & 91 & 88 & 95 \\
\hline \multirow[t]{2}{*}{ VaRR1 } & $\mathrm{DD}+$ & & & & & & & & 10 & 34 & 91 & 37 \\
\hline & DD- & & & & & & & & 55 & 35 & 0 & 17 \\
\hline \multirow[t]{2}{*}{$\overline{\mathrm{MAD}}$} & $\mathrm{DD}+$ & & & & & & & & & 74 & 96 & 79 \\
\hline & DD- & & & & & & & & & 0 & 0 & 0 \\
\hline \multirow[t]{2}{*}{$\overline{\mathrm{MM}}$} & $\mathrm{DD}+$ & & & & & & & & & & 91 & 52 \\
\hline & DD- & & & & & & & & & & 0 & 36 \\
\hline \multirow[t]{2}{*}{ Range } & $\mathrm{DD}+$ & & & & & & & & & & & 0 \\
\hline & DD- & & & & & & & & & & & 96 \\
\hline \multicolumn{13}{|c|}{ Panel B: Second order } \\
\hline & & ASR & SS & FT & GR5 & VaRR5 & GR1 & VaRR1 & MAD & MM & Range & Gini \\
\hline \multirow[t]{2}{*}{$\overline{\text { SR }}$} & $\mathrm{DD}+$ & 96 & 96 & 88 & 67 & 65 & 96 & 65 & 54 & 95 & 95 & 96 \\
\hline & DD- & 0 & 0 & 0 & 9 & 22 & 0 & 8 & 31 & 0 & 0 & 0 \\
\hline \multirow[t]{2}{*}{$\overline{\mathrm{ASR}}$} & $\mathrm{DD}+$ & & 96 & 87 & 64 & 63 & 96 & 42 & 39 & 90 & 95 & 96 \\
\hline & DD- & & 0 & 0 & 10 & 24 & 0 & 9 & 48 & 0 & 0 & 0 \\
\hline \multirow[t]{2}{*}{ SS } & DD+ & & & 81 & 42 & 46 & 95 & 0 & 0 & 65 & 95 & 54 \\
\hline & DD- & & & 5 & 26 & 31 & 0 & 35 & 96 & 22 & 0 & 33 \\
\hline \multirow[t]{2}{*}{$\overline{\mathrm{FT}}$} & DD+ & & & & 0 & 18 & 93 & 0 & 3 & 41 & 92 & 5 \\
\hline & DD- & & & & 90 & 69 & 0 & 90 & 84 & 46 & 0 & 82 \\
\hline \multirow[t]{2}{*}{$\overline{\text { GR5 }}$} & DD+ & & & & & 34 & 92 & 7 & 16 & 50 & 90 & 24 \\
\hline & DD- & & & & & 44 & 0 & 50 & 58 & 26 & 0 & 21 \\
\hline \multirow[t]{2}{*}{ VaRR5 } & DD+ & & & & & & 95 & 21 & 28 & 54 & 94 & 30 \\
\hline & DD- & & & & & & 0 & 44 & 59 & 36 & 0 & 37 \\
\hline$\overline{\text { GR1 }}$ & DD+ & & & & & & & 0 & 0 & 0 & 0 & 0 \\
\hline & DD- & & & & & & & 91 & 96 & 90 & 87 & 96 \\
\hline$\overline{\text { VaRR1 }}$ & $\mathrm{DD}+$ & & & & & & & & 13 & 65 & 89 & 45 \\
\hline & DD- & & & & & & & & 48 & 16 & 0 & 0 \\
\hline$\overline{\mathrm{MAD}}$ & DD+ & & & & & & & & & 95 & 95 & 96 \\
\hline & DD- & & & & & & & & & 0 & 0 & 0 \\
\hline$\overline{\mathrm{MM}}$ & $\mathrm{DD}+$ & & & & & & & & & & 95 & 32 \\
\hline & DD- & & & & & & & & & & 0 & 54 \\
\hline Range & $\begin{array}{c}\text { DD+ } \\
\text { DD- }\end{array}$ & & & & & & & & & & & $\begin{array}{c}\text { T } \\
0 \\
05\end{array}$ \\
\hline
\end{tabular}

This table displays the results for the stochastic dominance comparison between cumulative returns on pairs of equally weighted portfolios. First- and second-order stochastic dominance results are provided in panels A and B, respectively. The stocks included in each portfolio were selected using the specific performance measure indicated in the first row and are rebalanced at a monthly frequency. See Table 2 for the definitions. The returns are daily for the period between January 2006 and September 2014. DD+ (DD-) refers to the percentage of Davidson-Duclos (2000) significant positive (negative) test statistics. See Section 4.4 for details. 
Table 5

Stochastic dominance: Value weighted portfolios with monthly rebalancing.

\begin{tabular}{|c|c|c|c|c|c|c|c|c|c|c|c|c|}
\hline \multicolumn{13}{|c|}{ Panel A: First order } \\
\hline & & ASR & SS & FT & GR5 & VaRR5 & GR1 & VaRR1 & MAD & MM & Range & Gini \\
\hline \multirow[t]{2}{*}{$\overline{\mathrm{SR}}$} & $\mathrm{DD}+$ & 50 & 96 & 91 & 13 & 72 & 98 & 66 & 69 & 98 & 97 & 81 \\
\hline & DD- & 25 & 0 & 0 & 73 & 10 & 0 & 6 & 8 & 0 & 0 & 0 \\
\hline \multirow[t]{2}{*}{$\overline{\mathrm{ASR}}$} & $\mathrm{DD}+$ & & 96 & 83 & 14 & 74 & 98 & 65 & 65 & 98 & 97 & 92 \\
\hline & DD- & & 0 & 0 & 74 & 7 & 0 & 17 & 12 & 0 & 0 & 0 \\
\hline \multirow[t]{2}{*}{$\overline{S S}$} & $\mathrm{DD}+$ & & & 5 & 0 & 42 & 98 & 27 & 0 & 97 & 97 & 0 \\
\hline & DD- & & & 75 & 88 & 22 & 0 & 46 & 96 & 0 & 0 & 96 \\
\hline \multirow[t]{2}{*}{$\overline{\mathrm{FT}}$} & $\mathrm{DD}+$ & & & & 2 & 68 & 94 & 34 & 0 & 93 & 93 & 21 \\
\hline & DD- & & & & 83 & 14 & 0 & 21 & 80 & 0 & 0 & 49 \\
\hline \multirow[t]{2}{*}{$\overline{\text { GR5 }}$} & $\mathrm{DD}+$ & & & & & 91 & 94 & 93 & 77 & 94 & 93 & 75 \\
\hline & DD- & & & & & 0 & 0 & 0 & 5 & 0 & 0 & 9 \\
\hline \multirow[t]{2}{*}{$\overline{\text { VaRR5 }}$} & $\mathrm{DD}+$ & & & & & & 90 & 26 & 9 & 89 & 83 & 10 \\
\hline & DD- & & & & & & 0 & 49 & 73 & 0 & 0 & 70 \\
\hline \multirow[t]{2}{*}{$\overline{\text { GR1 }}$} & $\mathrm{DD}+$ & & & & & & & 0 & 0 & 30 & 0 & 0 \\
\hline & DD- & & & & & & & 92 & 98 & 46 & 83 & 98 \\
\hline \multirow[t]{2}{*}{$\overline{\text { VaRR1 }}$} & $\mathrm{DD}+$ & & & & & & & & 15 & 91 & 83 & 24 \\
\hline & DD- & & & & & & & & 55 & 0 & 0 & 52 \\
\hline \multirow[t]{2}{*}{$\overline{\mathrm{MAD}}$} & $\mathrm{DD}+$ & & & & & & & & & 98 & 97 & 59 \\
\hline & DD- & & & & & & & & & 0 & 0 & 19 \\
\hline \multirow{2}{*}{$\overline{\mathrm{MM}}$} & $\mathrm{DD}+$ & & & & & & & & & & 0 & 0 \\
\hline & DD- & & & & & & & & & & 96 & 98 \\
\hline \multirow[t]{2}{*}{ Range } & $\mathrm{DD}+$ & & & & & & & & & & & 0 \\
\hline & DD- & & & & & & & & & & & 97 \\
\hline \multicolumn{13}{|c|}{ Panel B: Second order } \\
\hline & & ASR & SS & FT & GR5 & VaRR5 & GR1 & VaRR1 & MAD & MM & Range & Gini \\
\hline \multirow[t]{2}{*}{$\overline{\mathrm{SR}}$} & DD+ & 47 & 97 & 91 & 0 & 66 & 98 & 78 & 65 & 98 & 98 & 98 \\
\hline & DD- & 45 & 0 & 0 & 91 & 10 & 0 & 0 & 29 & 0 & 0 & 0 \\
\hline \multirow[t]{2}{*}{$\overline{\mathrm{ASR}}$} & $\mathrm{DD}+$ & & 98 & 95 & 0 & 70 & 98 & 71 & 97 & 98 & 98 & 97 \\
\hline & DD- & & 0 & 0 & 91 & 6 & 0 & 0 & 0 & 0 & 0 & 0 \\
\hline \multirow[t]{2}{*}{ SS } & $\mathrm{DD}+$ & & & 0 & 0 & 54 & 98 & 0 & 0 & 98 & 97 & 0 \\
\hline & DD- & & & 91 & 92 & 22 & 0 & 87 & 97 & 0 & 0 & 97 \\
\hline \multirow[t]{2}{*}{$\overline{\text { FT }}$} & $\mathrm{DD}+$ & & & & 0 & 60 & 94 & 16 & 0 & 93 & 92 & 15 \\
\hline & DD- & & & & 91 & 15 & 0 & 44 & 93 & 0 & 0 & 65 \\
\hline \multirow[t]{2}{*}{$\overline{\text { GR5 }}$} & $\mathrm{DD}+$ & & & & & 92 & 93 & 92 & 91 & 93 & 92 & 91 \\
\hline & DD- & & & & & 0 & 0 & 0 & 0 & 0 & 0 & 0 \\
\hline \multirow[t]{2}{*}{$\overline{\text { VaRR5 }}$} & $\mathrm{DD}+$ & & & & & & 88 & 18 & 8 & 87 & 85 & 11 \\
\hline & DD- & & & & & & $\begin{array}{c}\text { Oo } \\
0\end{array}$ & $\begin{array}{l}10 \\
61\end{array}$ & $\begin{array}{l}0 \\
67\end{array}$ & $\begin{array}{c}07 \\
0\end{array}$ & $\begin{array}{c}0.5 \\
0\end{array}$ & $\begin{array}{l}11 \\
64\end{array}$ \\
\hline$\overline{\text { GR1 }}$ & $\mathrm{DD}+$ & & & & & & & 0 & 0 & 46 & 0 & 0 \\
\hline & DD- & & & & & & & 91 & 98 & 33 & 84 & 98 \\
\hline$\overline{\text { VaRR1 }}$ & DD+ & & & & & & & & 0 & 90 & 88 & 26 \\
\hline & DD- & & & & & & & & 62 & 0 & 0 & 41 \\
\hline$\overline{\mathrm{MAD}}$ & $\mathrm{DD}+$ & & & & & & & & & 98 & 98 & 97 \\
\hline & DD- & & & & & & & & & 0 & 0 & 0 \\
\hline$\overline{\mathrm{MM}}$ & $\mathrm{DD}+$ & & & & & & & & & & 0 & 0 \\
\hline & DD- & & & & & & & & & & 97 & 98 \\
\hline Range & $\begin{array}{l}\text { DD+ } \\
\text { DD- }\end{array}$ & & & & & & & & & & & $\begin{array}{c}0 \\
98\end{array}$ \\
\hline
\end{tabular}

This table displays the results for the stochastic dominance comparison between cumulative returns on pairs of equally weighted portfolios. First- and second-order stochastic dominance results are provided in panels A and B, respectively. The stocks included in each portfolio were selected using the specific performance measure indicated in the first row and are rebalanced at a monthly frequency. See Table 2 for the definitions. The returns are daily for the period between January 2006 and September 2014. DD+ (DD-) refers to the percentage of Davidson-Duclos (2000) significant positive (negative) test statistics. See Section 4.4 for details. 
Table 6

Risk factors sensitivities. Monthly returns from January 2006 to September 2014.

\begin{tabular}{|c|c|c|c|c|c|c|c|c|c|}
\hline & Intercept & $\mathrm{R}_{M}-\mathrm{R}_{F}$ & $S M B$ & $H M L$ & $R M W$ & $C M A$ & WML & $Q M J$ & $\left.R^{2} \%\right)$ \\
\hline \multirow[t]{2}{*}{ SR } & 0.0391 & 0.7171 & 0.3711 & 0.0097 & 0.2885 & -0.8016 & 0.2343 & -0.1883 & 64.78 \\
\hline & 12.66 & 7.26 & 2.60 & 0.06 & 1.07 & -3.17 & 3.38 & -0.80 & 62.24 \\
\hline \multirow[t]{2}{*}{ ASR } & 0.0396 & 0.7108 & 0.3671 & 0.0194 & 0.2389 & -0.8278 & 0.2328 & -0.1698 & 64.92 \\
\hline & 12.92 & 7.25 & 2.59 & 0.12 & 0.89 & -3.30 & 3.38 & -0.73 & 62.38 \\
\hline \multirow[t]{2}{*}{ SS(10) } & 0.0396 & 0.7608 & 0.3692 & 0.0275 & $\begin{array}{l}0.1098 \\
\end{array}$ & -0.7296 & 0.2301 & -0.0448 & 63.89 \\
\hline & 12.48 & 7.49 & 2.51 & 0.17 & 0.40 & -2.81 & 3.22 & -0.19 & 61.28 \\
\hline \multirow{2}{*}{$\operatorname{sS}(3)$} & 0.0414 & 0.6960 & 0.3799 & 0.0397 & 0.1328 & -0.8950 & 0.2301 & -0.0977 & 63.61 \\
\hline & 13.32 & 7.01 & 2.65 & 0.25 & 0.49 & -3.52 & 3.30 & -0.41 & 60.98 \\
\hline \multirow[t]{2}{*}{$\operatorname{SS}(2)$} & 0.0410 & 0.7161 & 0.3768 & 0.0453 & 0.1634 & -0.8502 & 0.2166 & -0.0663 & 64.25 \\
\hline & 13.43 & 7.34 & 2.67 & 0.29 & 0.61 & -3.40 & 3.16 & -0.29 & 61.68 \\
\hline \multirow[t]{2}{*}{$\mathrm{SS}(1.5)$} & 0.0409 & 0.7139 & 0.3307 & 0.0055 & 0.1490 & -0.7846 & 0.2207 & -0.1280 & 64.88 \\
\hline & 13.54 & 7.40 & 2.37 & 0.04 & 0.57 & -3.18 & 3.25 & -0.56 & 62.34 \\
\hline \multirow[t]{2}{*}{$\mathrm{SS}(0.8)$} & 0.0389 & 0.7266 & 0.3669 & -0.0024 & 0.1571 & -0.8430 & 0.2131 & -0.0878 & 65.39 \\
\hline & 12.88 & 7.53 & 2.63 & -0.02 & 0.60 & -3.41 & 3.14 & -0.38 & 62.90 \\
\hline \multirow[t]{2}{*}{$\mathrm{SS}(0.5)$} & 0.0385 & 0.7495 & 0.3792 & -0.0342 & 0.1254 & -0.8824 & 0.2096 & -0.0717 & 65.75 \\
\hline & 12.50 & 7.61 & 2.66 & -0.22 & 0.47 & -3.50 & 3.03 & -0.31 & 63.28 \\
\hline \multirow{2}{*}{$\mathrm{FT}(0.5,2)$} & $\begin{array}{c}0.0379 \\
\end{array}$ & 0.8004 & 0.2212 & -0.0133 & 0.4137 & -0.8916 & 0.2935 & -0.3471 & 64.27 \\
\hline & 11.08 & 7.31 & 1.40 & -0.08 & 1.38 & -3.18 & 3.81 & -1.34 & 61.69 \\
\hline \multirow[t]{2}{*}{$\mathrm{FT}(1.5,2)$} & 0.0413 & 0.6179 & 0.2430 & 0.2158 & -0.1079 & -0.7615 & 0.1498 & -0.0675 & 59.75 \\
\hline & 13.12 & 6.14 & 1.67 & 1.36 & -0.39 & -2.96 & 2.12 & -0.28 & 56.85 \\
\hline \multirow[t]{2}{*}{$\mathrm{FT}(1,1)$} & 0.0402 & 0.7086 & 0.3455 & 0.0187 & 0.1149 & -0.8094 & 0.2024 & -0.0608 & 64.66 \\
\hline & 13.55 & 7.47 & 2.52 & 0.12 & 0.44 & -3.33 & 3.03 & -0.27 & 62.11 \\
\hline \multirow{2}{*}{$\mathrm{FT}(2,1.5)$} & 0.0343 & 0.6993 & 0.2499 & 0.0498 & -0.2538 & -0.5841 & 0.0721 & 0.0368 & 63.16 \\
\hline & 11.11 & 7.09 & 1.75 & 0.32 & -0.94 & -2.31 & 1.04 & 0.16 & 60.50 \\
\hline \multirow[t]{2}{*}{$\operatorname{FT}(3,0.5)$} & 0.0267 & 0.8918 & 0.1958 & 0.2020 & -0.1865 & -1.0362 & 0.0228 & -0.1769 & 66.41 \\
\hline & 6.56 & 6.85 & 1.04 & 0.98 & -0.52 & -3.11 & 0.25 & -0.57 & 63.98 \\
\hline \multirow[t]{2}{*}{$\mathrm{FT}(1,2)$} & 0.0420 & 0.6936 & 0.2884 & 0.1597 & 0.1711 & -0.8456 & 0.2183 & -0.1429 & 63.72 \\
\hline & 13.64 & 7.04 & 2.02 & 1.03 & 0.64 & -3.35 & 3.15 & -0.61 & 61.10 \\
\hline \multirow{2}{*}{ GR5 $(0.8,0.001)$} & 0.0307 & 0.7231 & 0.2096 & $\begin{array}{c}0.2199 \\
\end{array}$ & $\begin{array}{l}-0.4190 \\
\end{array}$ & -0.4765 & -0.0337 & 0.2563 & 60.44 \\
\hline & 9.26 & 6.82 & 1.37 & 1.31 & -1.45 & -1.75 & -0.45 & 1.02 & 57.59 \\
\hline \multirow[t]{2}{*}{ GR5 $(0.5,0.8)$} & 0.0300 & 0.7231 & 0.2594 & 0.2386 & -0.3135 & -0.4663 & -0.0199 & 0.2323 & 62.24 \\
\hline & 9.37 & 7.06 & 1.75 & 1.47 & -1.12 & -1.78 & -0.28 & 0.96 & 59.51 \\
\hline GR5 $(0.8,0.8)$ & 0.0309 & 0.7239 & 0.2362 & 0.2524 & -0.4275 & -0.4716 & -0.0057 & 0.2693 & 60.83 \\
\hline & 9.38 & 6.88 & 1.55 & 1.52 & -1.49 & -1.75 & -0.08 & 1.08 & 58.00 \\
\hline GR5 $(0.5,1)$ & 0.0318 & 0.7131 & 0.1984 & 0.2764 & -0.4234 & -0.5396 & -0.0253 & 0.2630 & 60.39 \\
\hline & 9.60 & 6.74 & 1.30 & 165 & -1.47 & -1.99 & -0.34 & 1.05 & 57.54 \\
\hline GR5 $(0.01,0.8)$ & 0.0290 & 0.7720 & 0.3046 & 0.2627 & -0.2649 & -0.5593 & 0.0031 & 0.2722 & 63.44 \\
\hline & 8.96 & 7.45 & 2.03 & 1.60 & -0.94 & -2.11 & 0.04 & 1.11 & 60.80 \\
\hline GR5(1,1) & 0.0311 & 0.6793 & 0.2654 & 0.2251 & -0.4343 & -0.4626 & 0.0052 & 0.1694 & 61.59 \\
\hline & 9.54 & 6.53 & 1.76 & 1.37 & -1.53 & -1.74 & 0.07 & 0.69 & 58.82 \\
\hline VaRR5 & 0.0273 & 0.8025 & 0.1654 & 0.3667 & 0.0187 & $\begin{array}{c}-0.8982 \\
\end{array}$ & 0.0370 & $\begin{array}{l}-0.1426 \\
\end{array}$ & 72.29 \\
\hline & 8.70 & 7.99 & 1.14 & 2.31 & 0.07 & -3.49 & 0.52 & -0.60 & 70.29 \\
\hline GR1 $(0.8,0.001)$ & 0.0226 & 0.8044 & 0.2503 & 0.2399 & $\begin{array}{l}-0.4771 \\
\end{array}$ & -0.3695 & 0.0117 & 0.2364 & 66.68 \\
\hline & & 7.75 & 1.67 & 1. & & & 0.16 & 0.96 & 64.27 \\
\hline GR1 $(0.5,0.8)$ & 0.0222 & 0.7676 & 0.2741 & 0.2159 & -0.4542 & -0.3589 & 0.0162 & 0.1799 & 65.40 \\
\hline & 6.74 & 7.30 & 1.80 & 1.30 & -1.58 & -1.33 & 0.22 & 0.72 & 62.91 \\
\hline GR1 $(0.8,0.8)$ & 0.0229 & 0.7754 & 0.2746 & 0.2683 & -0.4683 & -0.3542 & 0.0014 & 0.2363 & 66.36 \\
\hline & 710 & 7.51 & 1.84 & 164 & -1.66 & -1.34 & 0.02 & 0.96 & 63.93 \\
\hline GR1 $(0.5,1)$ & 0.0218 & 0.7764 & 0.2918 & 0.2308 & -0.4561 & -0.3639 & 0.0148 & 0.2102 & 65.47 \\
\hline & 6.61 & 7.37 & 1.91 & 1.38 & -1.59 & -1.35 & 0.20 & 0.84 & 62.98 \\
\hline GR1 $(0.01,0.8)$ & 0.0215 & 0.7871 & 0.2818 & 0.1909 & -0.4461 & -0.3593 & 0.0021 & 0.2094 & 67.43 \\
\hline & 6.79 & 7.80 & 1.93 & 1.20 & -1.62 & -1.39 & 0.03 & 0.87 & 65.08 \\
\hline GR1 $(1,1)$ & 0.0226 & 0.7856 & 0.2714 & 0.2757 & -0.4711 & -0.3517 & 0.0060 & 0.2352 & 68.04 \\
\hline & 7.19 & 7.82 & 1.87 & 1.74 & -1.72 & -1.37 & 0.09 & 0.99 & 65.73 \\
\hline VaRR1 & 0.0204 & 0.9227 & 0.1281 & 0.3796 & -0.5713 & -0.3112 & 0.0285 & 0.4815 & 71.28 \\
\hline & 6.87 & 9.72 & 0.93 & 2.53 & -2.20 & -1.28 & 0.43 & 2.14 & 69.21 \\
\hline
\end{tabular}




\begin{tabular}{lccccccccc} 
MAD & 0.0398 & 0.7141 & 0.3644 & 0.0038 & 0.1306 & -0.8059 & 0.2083 & -0.0773 & 64.70 \\
& 13.22 & 7.42 & 2.62 & 0.03 & 0.50 & -3.27 & 3.08 & -0.34 & 62.16 \\
\hline MinMax & 0.0325 & 0.8197 & 0.3133 & -0.0148 & 0.5813 & -0.6578 & 0.2628 & -0.2470 & 64.13 \\
& 9.86 & 7.78 & 2.06 & -0.09 & 2.02 & -2.44 & 3.55 & -0.99 & 61.54 \\
\hline Range & 0.0347 & 0.8194 & 0.2751 & -0.0361 & 0.4891 & -0.6779 & 0.2655 & -0.2284 & 64.13 \\
& 10.61 & 7.84 & 1.82 & -0.22 & 1.71 & -2.53 & 3.61 & -0.92 & 61.54 \\
\hline Gini & 0.0401 & 0.7325 & 0.3687 & 0.0271 & 0.1750 & -0.8128 & 0.2103 & -0.0614 & 64.98 \\
& 13.27 & 7.59 & 2.64 & 0.18 & 0.66 & -3.29 & 3.10 & -0.27 & 62.45 \\
\hline
\end{tabular}

This table reports the estimation of a model that includes the Fama-French five factors, the momentum factor and the quality factor. The dependent variable is the excess monthly returns on 32 portfolios constructed by equally weighting the 20 stocks selected by each performance measure. See Tables 1 and 2 for the definitions of the measures. The numbers in parentheses are $t$-statistics. 
Figure 1

Mean return-risk ratios

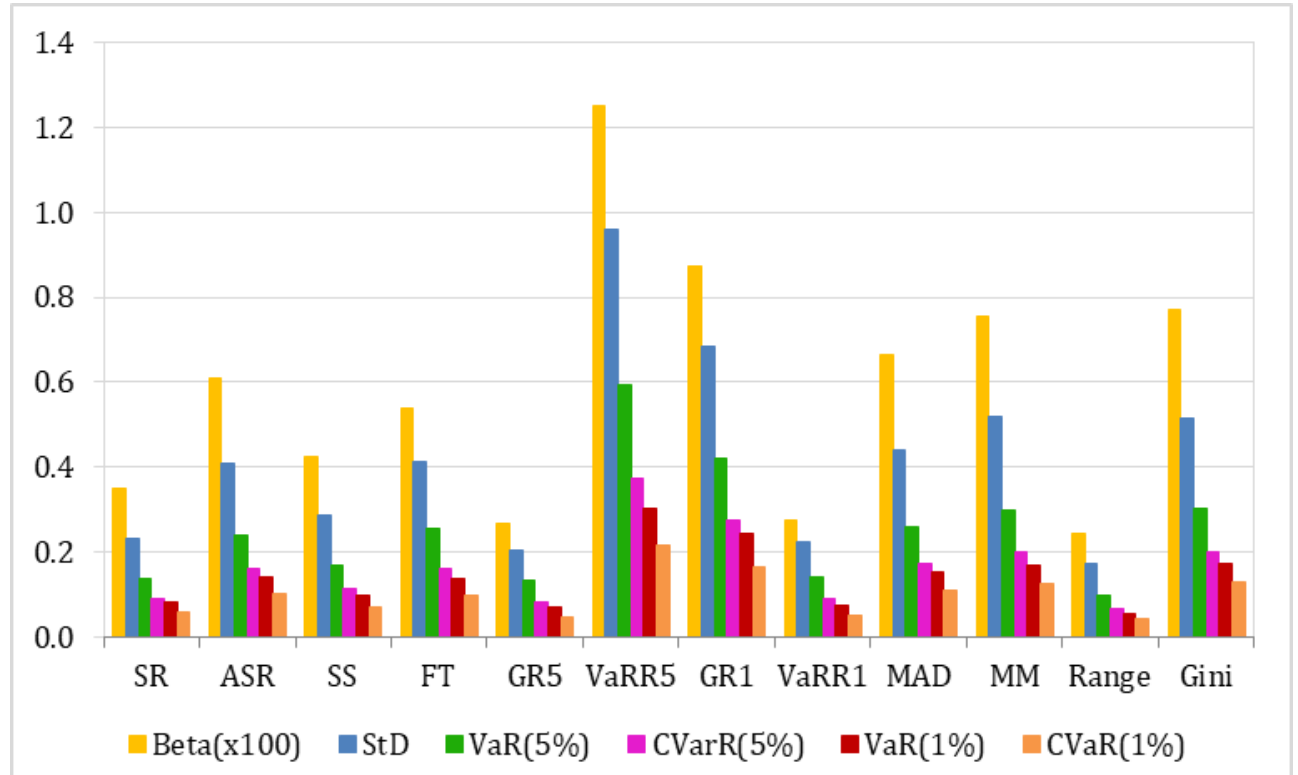

This figure displays the value of mean return-risk ratios computed from daily returns on 12 portfolios during the period between January 2006 and September 2014. The risk measure differs for each ratio and is indicated, as follows: the market beta (Beta), the standard deviation (StD), the value at risk (VaR), and the conditional value at risk $(\mathrm{CVaR})$. The numbers in parentheses indicate the confidence levels. The portfolios are constructed by equally weighting the 20 stocks selected on the basis of a pre-ranking that uses different performance measures. See Tables 1 and 2 for the definitions of the performance measures. 
Figure 2

Dynamic conditional correlations between the Sharpe-based portfolio and other portfolios

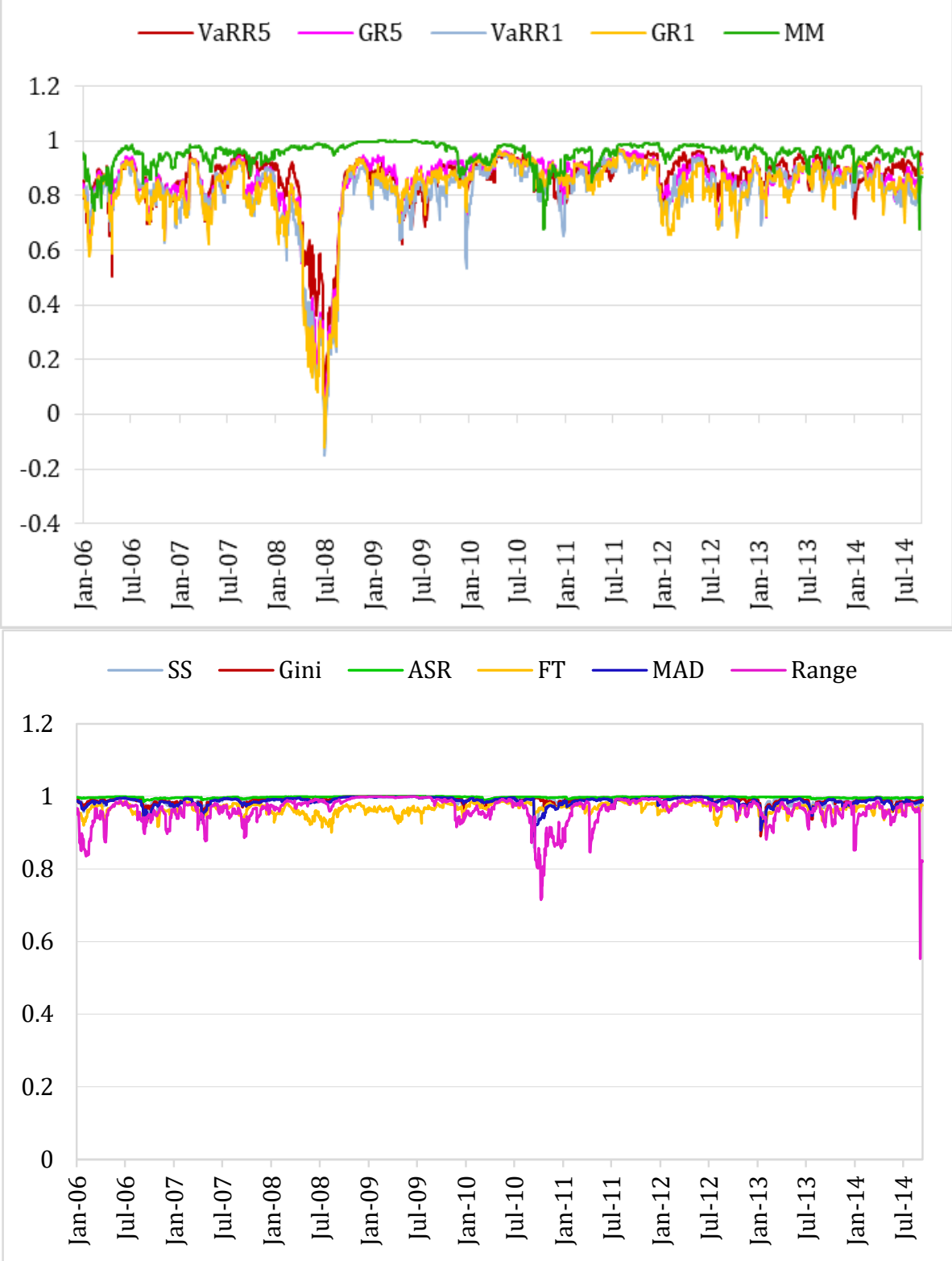

These graphs display the dynamic conditional correlations between the OOS returns on the Sharpe portfolio and each of the other portfolios, as indicated. See Tables 1 and 2 for the definitions. The returns are daily and refer to the period between January 2006 and September 2014. 
Figure 3

Spreads between cumulative returns on alternative portfolios and the Sharpe-based portfolio

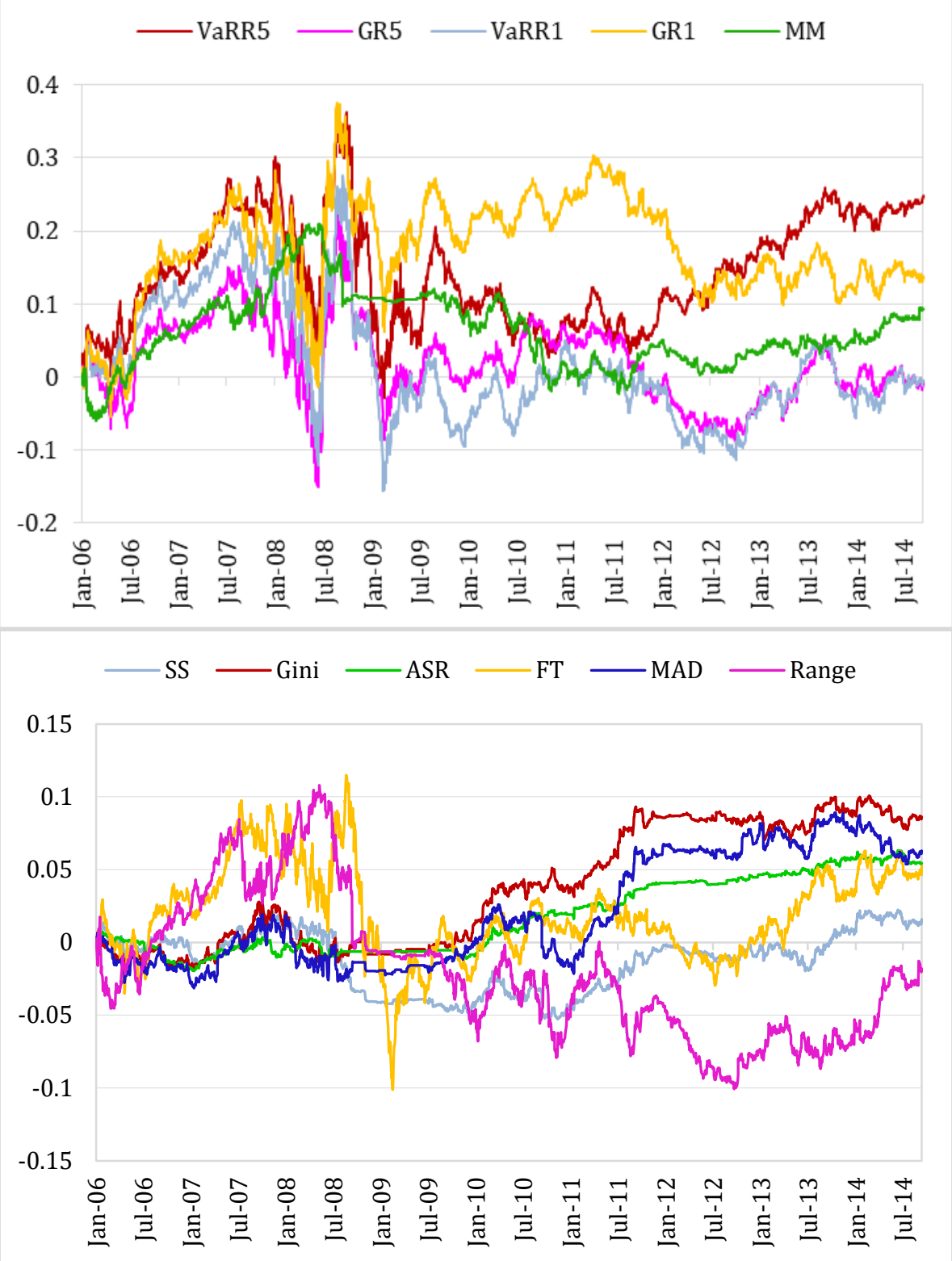

These figures display the difference between the cumulative OOS return on each of the portfolios, as indicated, and on the Sharpe portfolio. See Tables 1 and 2 for the definitions. The returns are daily and refer to the period between January 2006 and September 2014. 


\section{Figure 4}

Spreads between cumulative returns on alternative portfolios and the Sharpe-based portfolio: Monthly portfolio rebalancing.

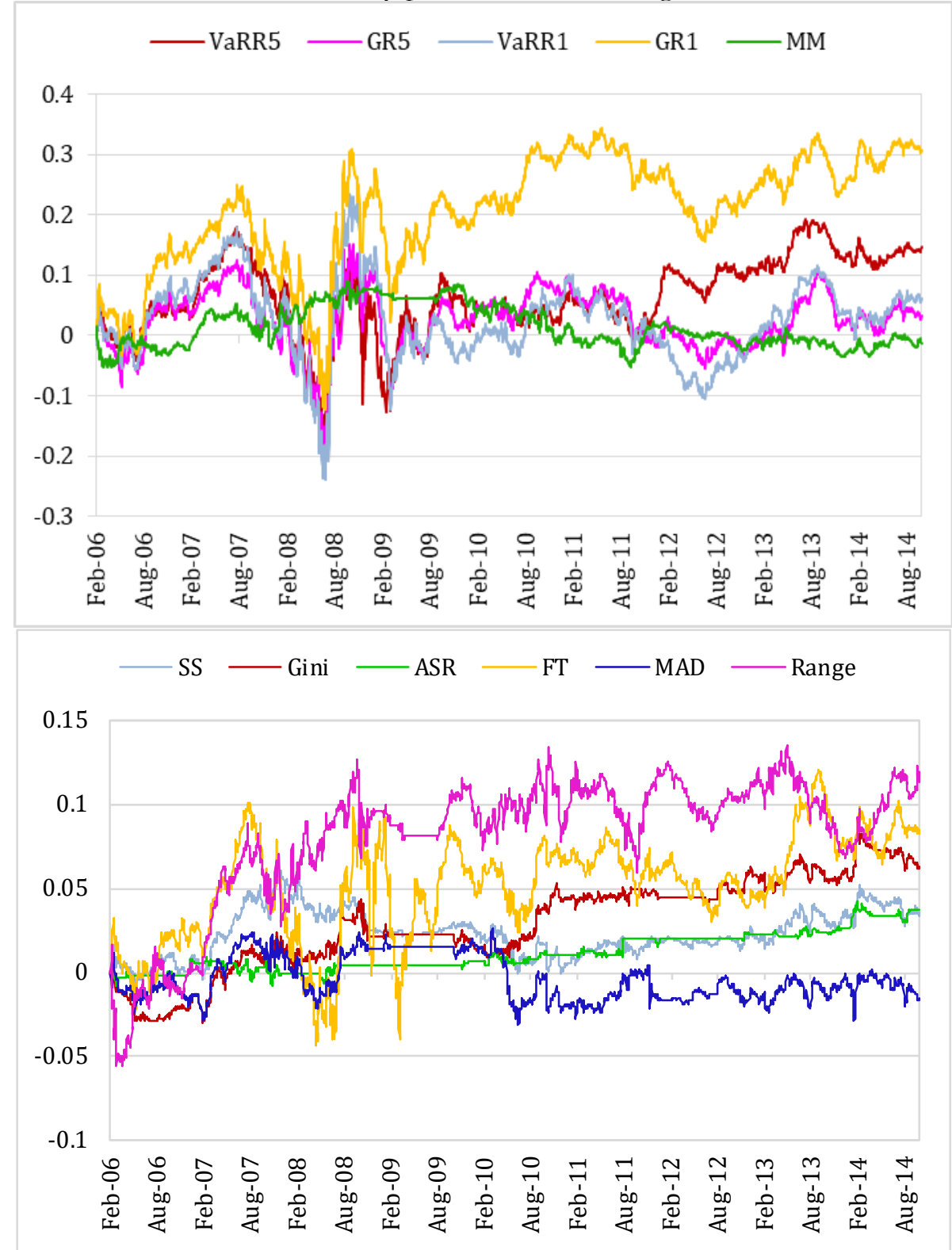

These figures display the difference between the cumulative return on each of the portfolios, as indicated, and on the Sharpe portfolio. See Tables 1 and 2 for the definitions. The portfolios are computed equally weighting the 20 stocks selected by each measure and are rebalanced monthly. The portfolio returns are daily and refer to the period between January 2006 and September 2014. 


\section{Figure 5}

Spreads between cumulative returns on alternative portfolios and the Sharpe-based portfolio: Value weighted portfolios with monthly rebalancing.

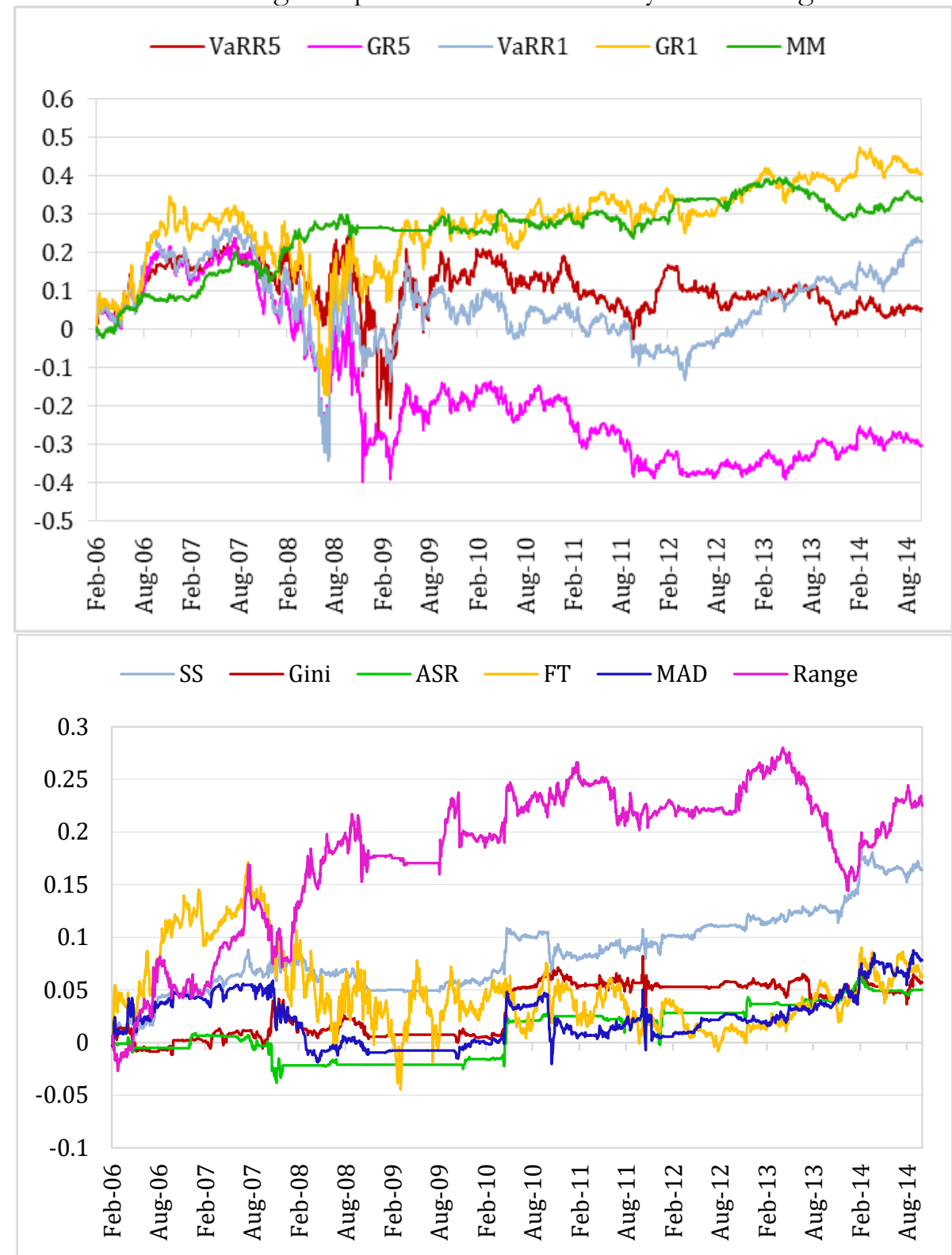

These figures display the difference between the cumulative return on each of the portfolios, as indicated, and on the Sharpe portfolio. See Tables 1 and 2 for the definitions. The portfolios are computed value weighting the 20 stocks selected by each measure and are rebalanced monthly. The portfolio returns are daily and refer to the period between January 2006 and September 2014. 
Figure 6

Rolling moments of in sample returns. Assets selected by the Sharpe or Generalized-Rachev ratios.
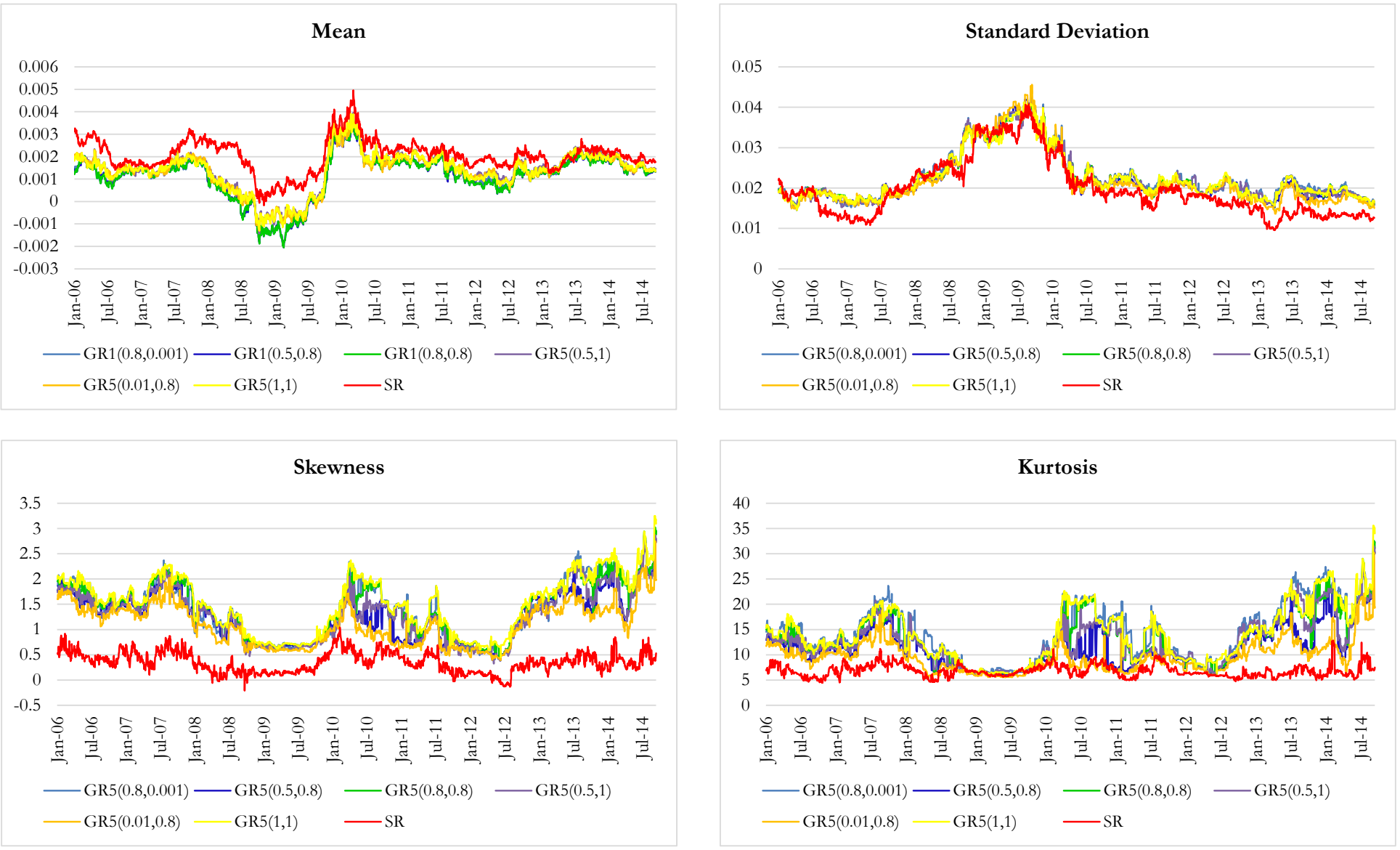

Each day, starting on January 19, 2006, all stocks are sorted on the basis of their Sharpe ratio and six Generalized Rachev ratios with different parameters. The best 20 stocks for each sorting are recorded. The four moments of returns are computed for each of these socks using the last 264 daily returns. The graphs show the daily time pattern of the average moments among the 20 stocks selected by each measure. 


\section{Figure 7}

Rolling skewness of in sample returns on stocks selected by GR5 and VaRR 5 measures and the momentum factor.

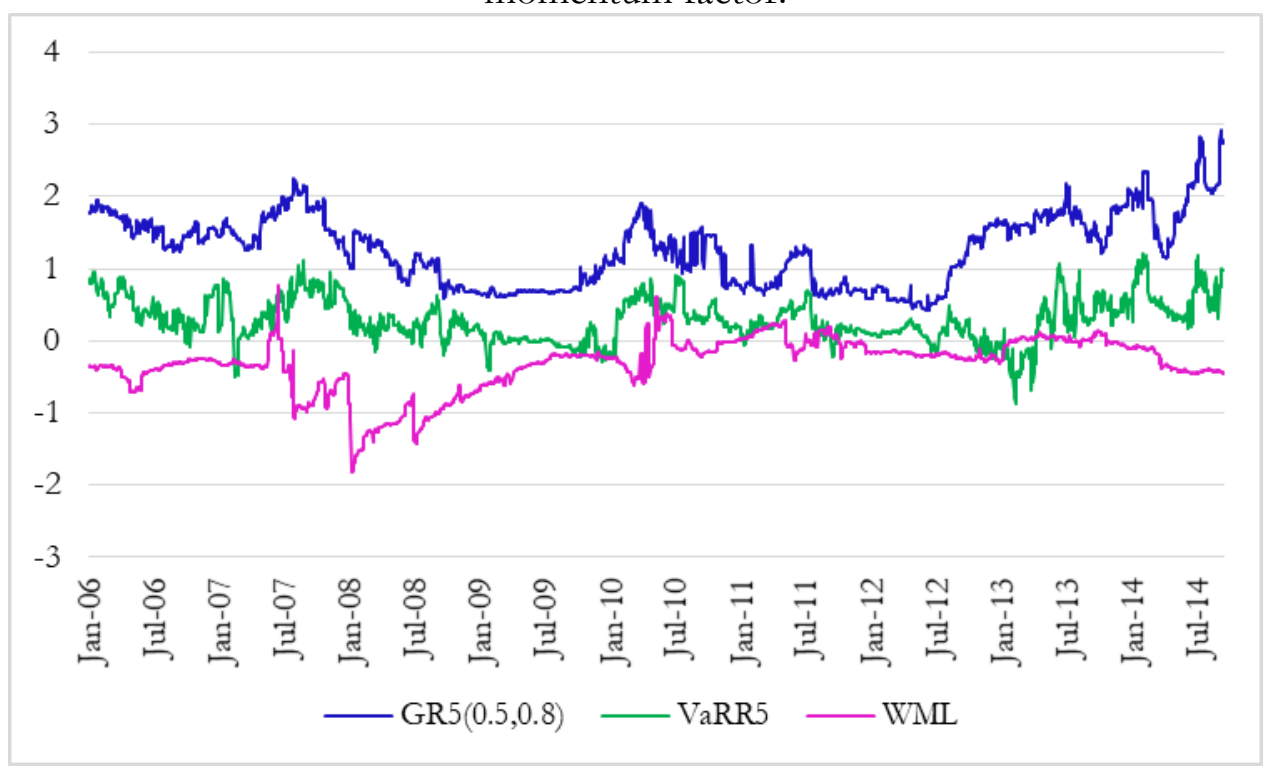

Each day, starting on January 19, 2006, all stocks are sorted on the basis of the Generalized Rachev and VaR ratios at $5 \%$ level of significance, computed with the last 264 daily returns. The best 20 stocks for each sorting are recorded. The picture shows the time varying skewness pattern of the stocks selected by each measure and the momentum factor. The rolling skewness is computed each day using past daily returns in the 264-day window. In case of GR and VaRR, series refer to the average of skewness among the 20 selected stocks. 